\title{
La génesis del Mundo lbérico en la submeseta sur: El tránsito del Bronce final- I Edad del Hierro en Alarcos
}

\author{
Rosario García Huerta* \\ Macarena Rodriguez **
}

\section{Resumen}

El objeto de este trabajo es dar a conocer un conjunto de cerámicas del Bronce Final-I Edad del Hierro de Alarcos, un oppidum situado en la margen izquierda del río Guadiana (Ciudad Real), que constituye uno de los yacimientos más completos en fase de estudio, ya que se ha documentado la presencia de poblamiento desde el Bronce Pleno hasta nuestros días. Estos materiales muestran el importante nivel de desarrollo alcanzado por Alarcos en estos momentos, equiparable al de Medellín o Cástulo, y viene a llenar el aparente vacío de poblamiento de la Submeseta Sur entre el final del Bronce Manchego y los inicios del Periodo Ibérico.

Palabras Clave. Meseta Sur, oppidum Alarcos, cerámica, Edad del Hierro.

\begin{abstract}
The aim of this research is to show a Bronze Age- I Iron Age pottery collection from Alarcos, a oppidum situated at left side of Guadiana river (Ciudad Real), which represents one of the most compledsite under studying whit human presence documented from Bronze Age until today. These materials prove the higt level of development in Alarcos in this era, similar to Medellin or Cástulo, and full the apparent human empty the South Meseta between the manchego bronze and the starts of the Iberian Period.

Keywords. South Meseta, oppidum Alarcos, pottery, Iron Age.
\end{abstract}

El período del Bronce Final - I Edad del Hierro en la submeseta sur y especialmente en la provincia de Ciudad Real es poco conocido, lo que contrasta con el de etapas anteriores, fundamentalmente con el denominado "Bronce de la Mancha", que viene siendo objeto de investigaciones desde hace unos veinte años. Los trabajos de síntesis realizados a principios de los años noventa (Blasco, 1992; Pereira, 1994) para el conjunto de la meseta sur constituyen un buen intento de aproximación a este período, aunque para la provincia de Ciudad Real había que lamentar la escasez de datos. Este panorama empezó a cambiar a raíz de la publicación de los resultados de las excavaciones arqueológicas que se vienen realizando en varios yacimientos de la provincia desde 1984, como Alarcos (Fernández et alii, 1995), La Bienvenida (Fernández Ochoa y Zarzalejos, 1992; Zarzalejos et alii, 1994), el Cerro de las Cabezas (Pérez Avilés y Vélez Rivas, 1994), el Cerro de las Nieves (Fernández

* Departamento de Historia. Area de Prehistoria. Universidad de Castilla-La Mancha.
Martínez et alii, 1994) y Peñarroya (García Huerta et alii, 1999 ).

En estos yacimientos han aparecido, bajo los niveles ibéricos, otros más antiguos que evidencian un poblamiento anterior, cuyo mejor y a veces único testimonio es la presencia de cerámicas a mano del Bronce Final-Hierro I. Ambos periodos son difíciles de individualizar en estos asentamientos, donde los contextos cerámicos se reducen, en el mejor de los casos, a pequeños espacios de dudosa funcionalidad situados en los estratos más profundos de algunos cortes estratigráficos.

En este trabajo estudiamos los materiales hallados en el cerro de Alarcos, un oppidum situado en la margen izquierda del río Guadiana a escasos kms. de Ciudad Real, que constituye uno de los yacimientos más completos en proceso de estudio, ya que se ha documentado una ocupación desde el Bronce hasta época medieval (Fernández et alii, 1995). Desde el punto de vista

\footnotetext{
** I.E.S. Comendador Juan de Távora. Puertollano (Ciudad Real).
} 


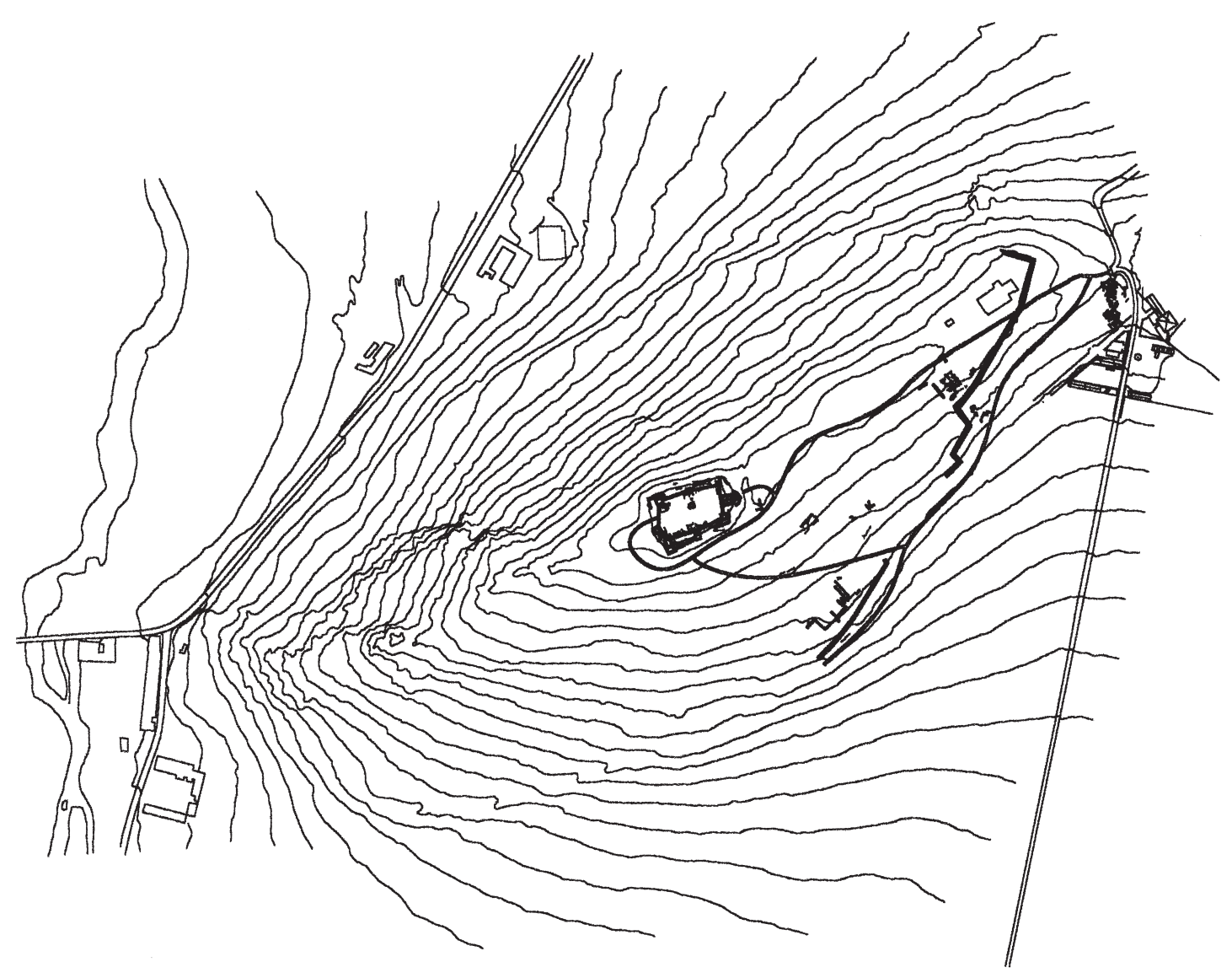

Figura 1. Topografía del cerro de Alarcos.

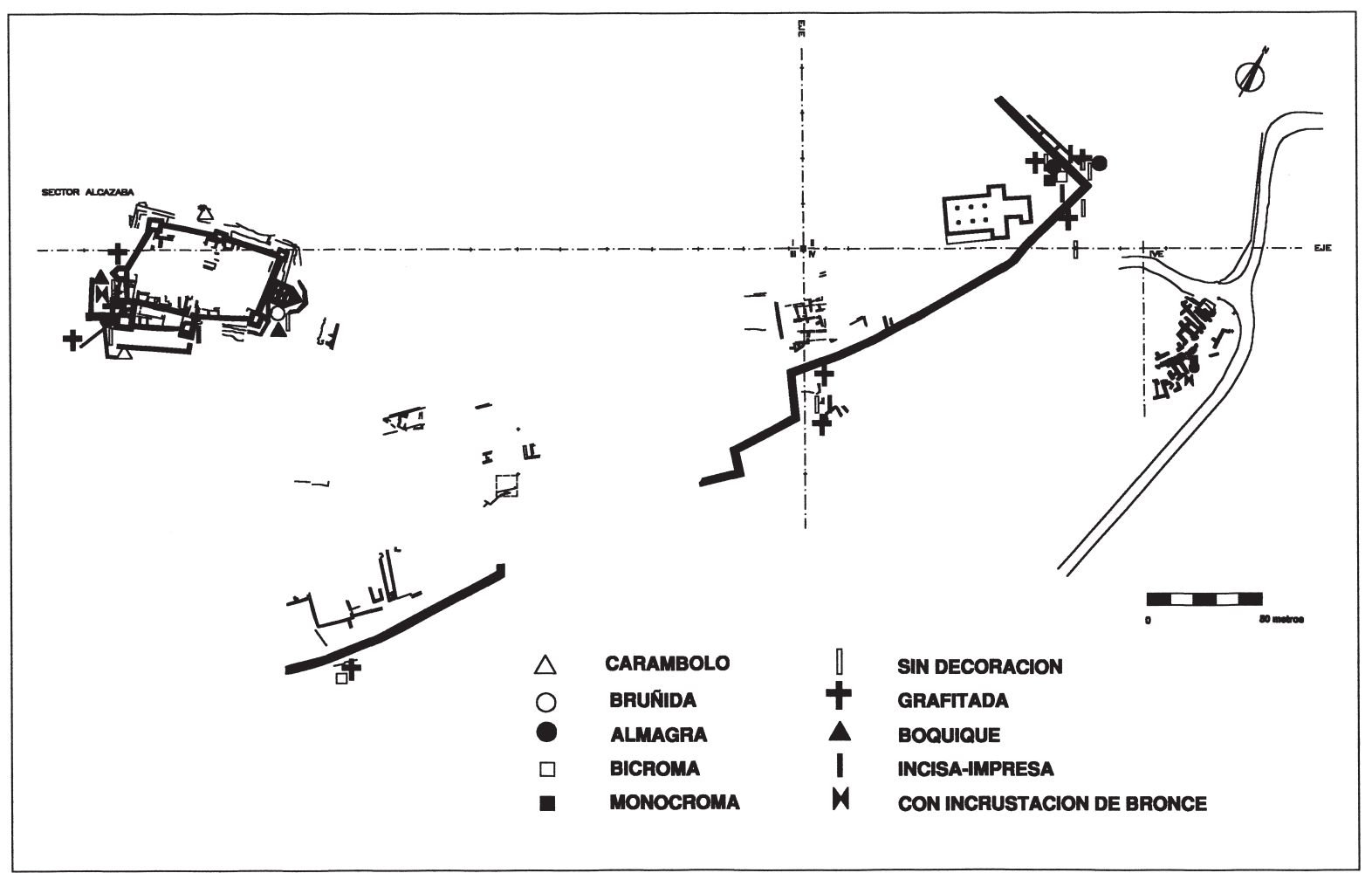

Figura 2. Distribución de los diferentes tipos de cerámica a mano en la zona excavada del yacimiento. 
metodológico el yacimiento se ha dividido en varios sectores: II, III, IV, IV-E y Alcazaba (fgs. 1 y 2). Las excavaciones arqueológicas se han centrado principalmente en las áreas del castillo, la muralla medieval y, en menor medida, en la zona ibérica. En ellas han ido apareciendo una serie de materiales arqueológicos que presentan una gran variedad y que permiten abordar el origen del poblamiento ibérico en este territorio. Los tipos cerámicos documentados son: cerámicas incisas, boquique, impresas, retícula bruñida, pintadas, grafitadas, con incrustaciones de bronce y cerámicas comunes.

En el sector II, donde se sitúa la emita de la Virgen de Alarcos, se encuentra la mayor concentración de estas piezas, superando en algunos cortes el 50\% del total cerámico. Sin embargo, es una zona bastante alterada debido a la proximidad de la ermita y a una esquina de la muralla medieval, circunstancias que han provocado la realización en diversas ocasiones de intervenciones de distinta índole y ha ocasionado una alteración e incluso destrucción de los estratos arqueológicos, que en esta zona no superan los 1,5 $\mathrm{m}$ de potencia. Sólo en algunos cortes se ha documentado un nivel de arcillas intactas sobre la roca madre, asociadas a cerámicas a mano, en ningún caso relacionadas con estructuras murarias. Destacan los pequeños recipientes con carenas altas, las cerámicas decoradas con ungulaciones y digitaciones, las grafitadas, las decoradas a la almagra y las pintadas monócromas en rojo y bícromas en rojo y amarillo.

En el sector III la excavación se ha centrado en la muralla medieval, en torno a la cual se han encontrado cerámicas a mano procedentes de los niveles alterados por la construcción de la fosa de fundación. Sólo en la cuadrícula 1035 se han encontrado niveles intactos con presencia de cerámica grafitada y pintura bícroma.

En el sector Alcazaba, situado en la zona más elevada del cerro, se han hallado cerámicas correspondientes a distintas etapas culturales, desde el Bronce Pleno a época medieval. Es en esta zona amesetada donde las cerámicas del Bronce Final ofrecen mayor variedad de tipos: incisas, incrustaciones de bronce, bruñidas, pintadas (tipo Carambolo, bícromas, monocromas), a la almagra y numerosas cerámicas sin decoración. Todas ellas están descontextualizadas y aparecen entre los derrumbes de tapial de los muros medievales.

También en el sector IV se han excavado las cuadrículas situadas a ambos lados de la muralla medieval. Aquí el yacimiento alcanza su máxima potencia arqueológica, superando los 10 m. En los niveles inferiores aparecen cerámicas a mano, que por el momento han podido aislarse en un área reducida, localizada en la zona de intramuros, asociadas a un nivel de arcilla que se asienta sobre la roca madre. Los cortes ubicados fuera de la muralla también se han visto intensamente afectados por las obras realizadas para la construcción de áquella. Pero en uno de ellos se conserva una pequeña área intacta, que muestra un paulatino aumento de las cerámicas a mano a medida que se profundiza, estando los niveles inferiores relacionados con estructuras de piedra de posibles habitaciones (Fernández, 2000:129). Se documentan en esta zona cerámicas grafitadas, pintadas, incisas, impresas, bruñidas, alisadas, etc.

El sector IV-E está situado fuera de la muralla medieval y próximo a los sectores II y IV. Es él se ha documentado parte del poblado ibérico y la única necrópolis localizada hasta el momento en Alarcos. De aquí proceden cerámicas decoradas a la almagra, con pintura monócroma, un recipiente pintado y otro con incrustaciones de bronce, una vasija gallonada, varias con digitaciones y numerosos fragmentos sin decoración.

En este trabajo pretendemos hacer un análisis exhaustivo de esos materiales arqueológicos, integrados exclusivamente por cerámicas, correspondientes a las etapas más antiguas de ocupación del cerro, y que a pesar de haberse hallado fuera de contexto, por su número y especialmente por sus características, nos permiten establecer la existencia de un horizonte claramente preibérico que se perfila cada vez con mayor nitidez, aunque todavía están por hallar esos materiales en contextos estratigráficos.

\section{Cerámica Incisa}

Esta técnica decorativa resulta habitual en la Península Ibérica desde el Neolítico, aunque los motivos decorativos y las formas a las que se asocia permiten identificar la adscripción cultural. El número de fragmentos decorados con esta técnica hallado en el cerro de Alarcos, hasta el momento, es de ocho, sin que se haya podido reconstruir ninguna forma entera. Se trata de fragmentos de pequeño tamaño de bordes, carenas y galbos. Las pastas son de color negro y rojizo, bastante compactas y bien depuradas, con desgrasantes de tamaño fino y medio. Las superficies son de color negro, gris y pardo rojizo, están bien acabadas en general y tres de los fragmentos presentan las superficies bruñidas. Este tipo cerámico se decora con incisiones hechas cuando el barro está fresco y se realiza con un objeto de punta aguzada. Las punzadas pueden 

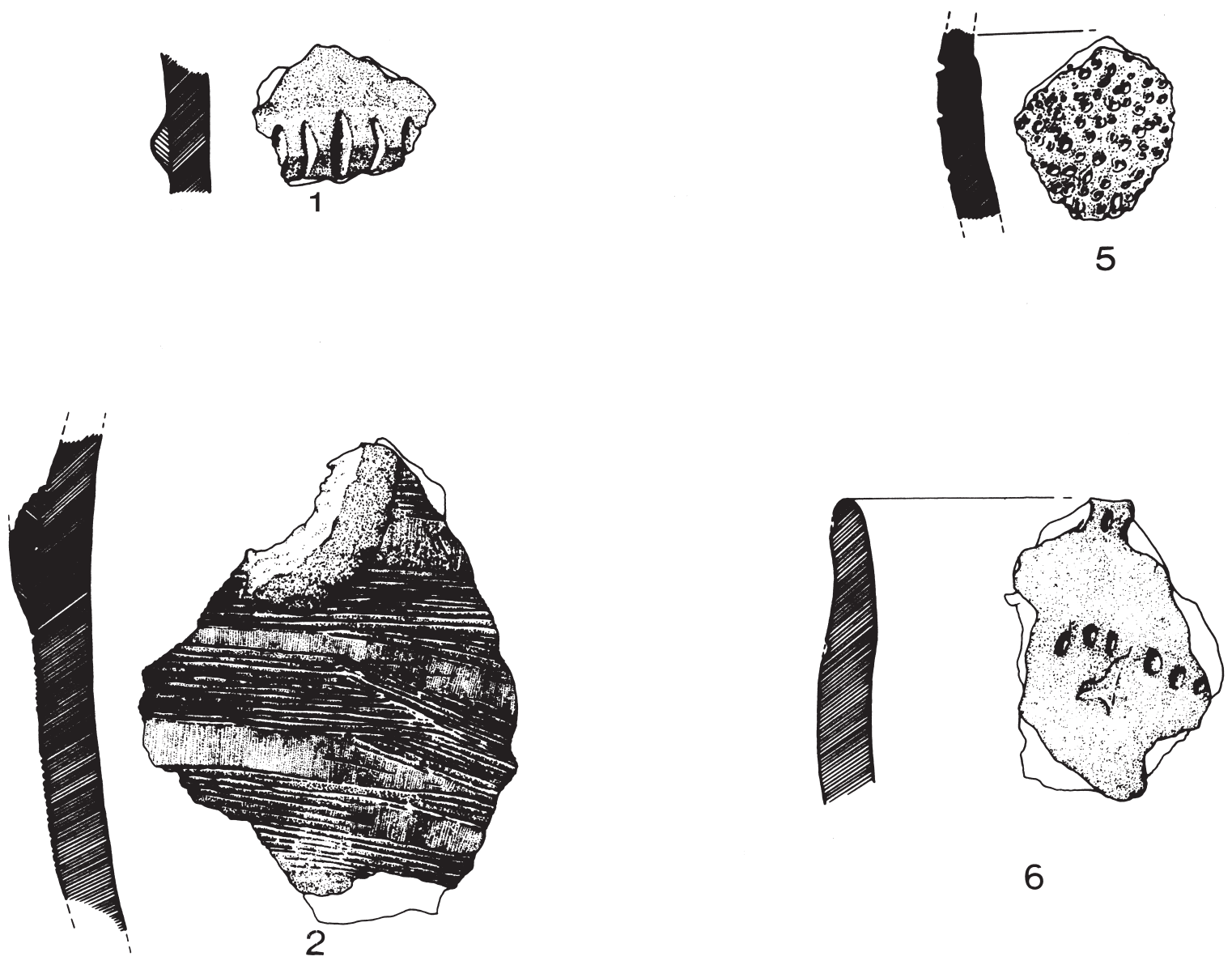

6
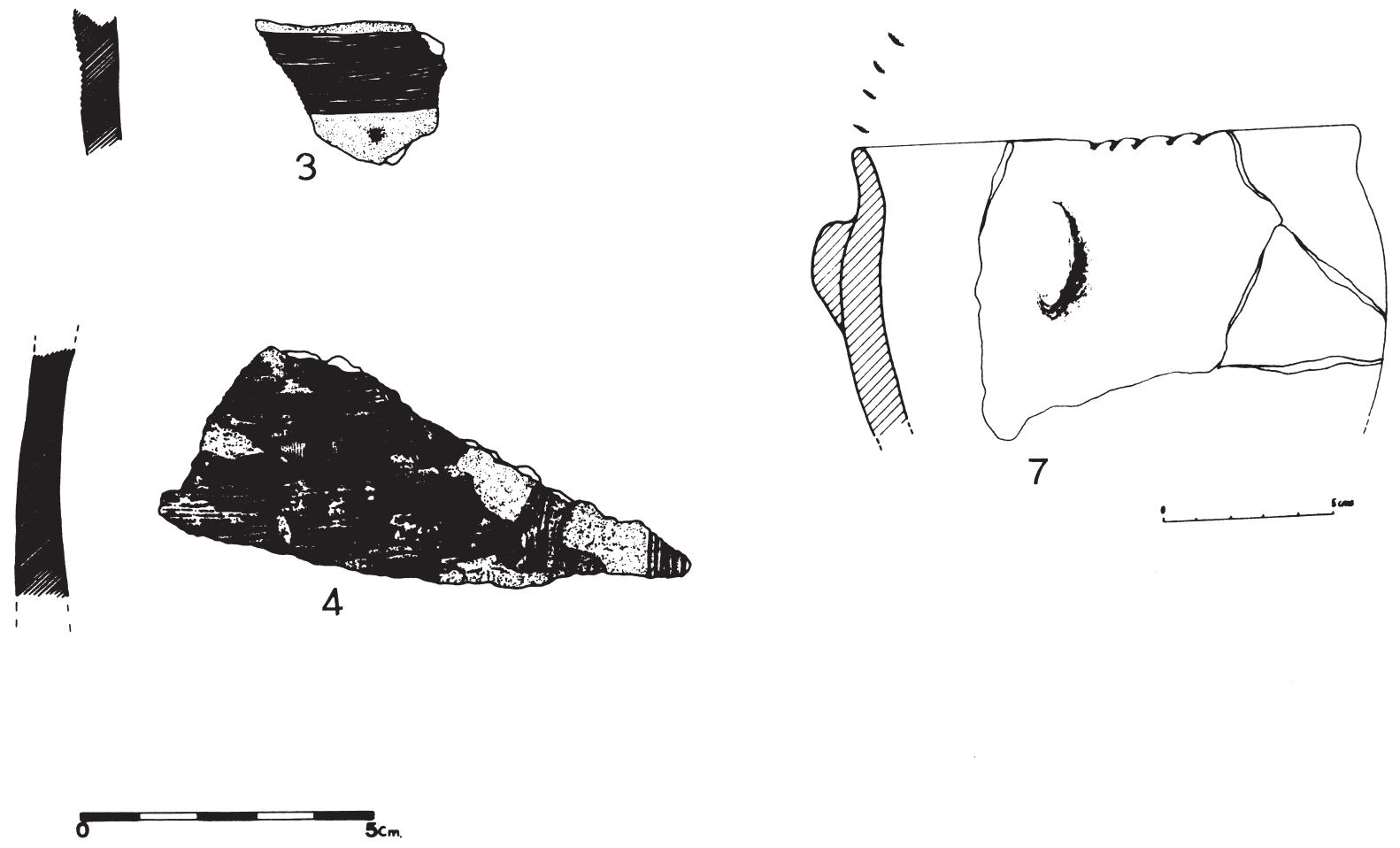

Figura 3. Cerámicas incisas: 1, 2, 3 y 4. Cerámicas impresas: 5, 6 y 7 
ser más o menos gruesas y cortas (fg. 3:1) o formando motivos de líneas quebradas y ángulos, que en tres casos se rellenan con pasta blanca (fg. 4: 2, 3 y 5). En otros fragmentos las incisiones son largas y profundas formando bandas anchas o cubriendo irregularmente toda la superficie (fg. 3: 2, 3 y 4). Los fragmentos con motivos incisos rellenos con pasta blanca se hallaron en el nivel superficial y en el nivel II del sector Alcazaba. El resto de los fragmentos incisos se localizaron en el sector IV.

Las cerámicas incisas se conocen en contextos culturales muy diversos, lo que unido a la ausencia de formas completas dificulta un encuadre cultural y cronológico preciso, por lo que su estudio debe ponerse en relación con otros tipos cerámicos, como las impresas y de boquique. De los fragmentos encontrados en Alarcos resultan especialmente interesantes los que están rellenos de pasta blanca, ya que este tipo se vincula a la cultura de Cogotas I, que trataremos unas líneas más abajo.

En yacimientos cercanos, como El Cerro de Las Cabezas de Valdepeñas (Vélez y Pérez, 1987) y Cástulo (Blázquez y Valiente, 1983) aparecen cerámicas con motivos decorativos muy similares a los de Alarcos fechados en los ss.VIII-VII a.C.

\section{Cerámica Impresa}

Este es un tipo decorativo muy representado en el yacimiento de Alarcos, especialmente las ungulaciones en el borde de los recipientes que aparecen en casi todas las zonas excavadas. Sólo en dos fragmentos se sitúan estos motivos en la pared exterior; en un fragmento se documentan dos filas de digitaciones ovaladas bajo el borde (fg.3:6). El otro fragmento presenta su superficie exterior con impresiones hechas con punzón (fg.3:5).

Las cerámicas impresas son tan abundantes en diferentes contextos culturales que resultan poco representativas, sobre todo cuando se trata de un número de fragmentos tan pequeños y por tanto poco significativos. Está técnica decorativa está presente en todos los yacimientos cercanos a Alarcos en los que se documenta un horizonte protoibérico. Así en la Bienvenida se encuentra desde el s.VIII al VI a.C. aunque el número de fragmentos conservados no es muy abundante, las investigadoras de este yacimiento vinculan este tipo cerámico con la existencia de prácticas mineras (Fernández Ochoa, et alii, 1994:70). En todo caso se trata de una cerámica tosca de carácter utilitario que sería fabricada en los poblados y en ningún caso sería objeto de comercio.

\section{Cerámica de Boquique}

Esta técnica decorativa consistente en pequeñas impresiones dentro de la incisión continua, más conocida por punto y raya, está escasamente representada en este yacimiento y se reduce a un único fragmento que procede de la Alcazaba. Se trata de un galbo con una carena baja, hecho a mano, con pasta y superficies negras bruñidas de gran calidad, presenta en la pared exterior una decoración de boquique, a base de líneas horizontales paralelas hechas con punto y raya, y una vertical que enmarca otras dos líneas (fg. 4:1).

La cerámica de boquique se vincula de forma casi exclusiva a la cultura de Cogotas I y se acepta de forma casi unánime su carácter indígena, aunque ya hace bastantes años que FernándezPosse (1982:139) en un interesante trabajo sobre este tipo cerámico, llamó la atención sobre la existencia de cerámicas de boquique que no pertenecen a Cogotas I, sino a contextos neolíticos tardíos.

Este horizonte de Cogotas I ha sido y sigue siendo, desde su definición como tal, objeto de constantes revisiones en cuanto a su dispersión geográfica, que cada día se revela más amplia, ya que en un primer momento se consideró como una cultura estrictamente meseteña, de la Meseta Norte, mientras que hoy el área de dispersión se ha ampliado al norte de Portugal, valle del Ebro, Levante, Andalucía, Extremadura y la Meseta Sur. También ha experimentado grandes cambios su cronología, que empezó definiéndose como una cultura de la Edad del Hierro para pasar después a la Edad del Bronce. Delibes y sus colaboradores (1995: 155 y ss.) señalan la falta de series largas de fechas absolutas en la Meseta para Cogotas I, lo que dificulta el establecimiento de su momento final, pero la serie de fechas obtenidas en el yacimiento del Soto de Medinilla le permite situar el inicio del grupo de Soto entre el 1000 y el 900, en un momento inmediatamente después del final de Cogotas I.

En el ámbito geográfico de la Meseta Sur hay pocos datos sobre Cogotas I, en el trabajo de Fernández-Posse (1982), se incluye un mapa de dispersión de hallazgos de cerámica de boquique en el que aparecen los yacimientos de Mocejón y Mora en Toledo y el de Malagón en Ciudad Real. Posteriormente Blasco (1992) pone de manifiesto la presencia de Cogotas I en la zona citada y enumera un gran número de hallazgos en esta zona, especialmente en la provincia de Toledo, como los de Mocejón y Mora, a los que añade Albarreal de Tajo, Herencias, Malpica, Zayos, Finca de Hidalgos etc. En la provincia de Ciudad Real vuelve a citar el yacimiento de 

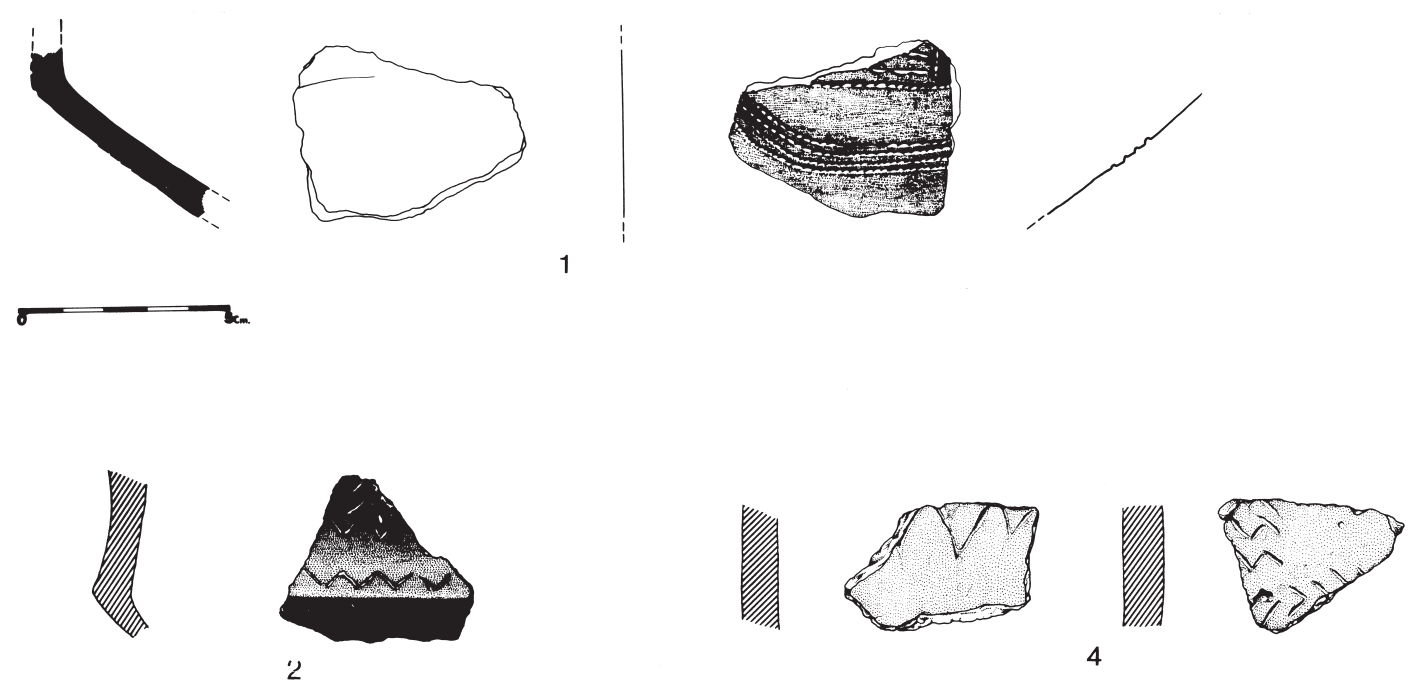

4
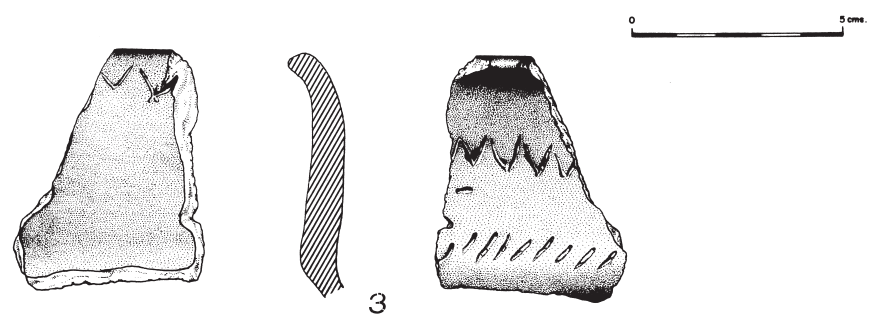

Figura 4. Cerámica de boquique: 1. Cerámicas incisas rellenas de pasta blanca: 2, 3 y 5. Cerámica incisa: 4.

Malagón e incorpora uno nuevo, el de Alarcos. Esta autora plantea la existencia de grupos de Cogotas I en la Meseta Sur que empezarían a declinar hacia el s.VIII a.C., cuando se incrementan los contactos entre esta zona, especialmente los territorios más meridionales, con el valle del Guadalquivir, lo que dará lugar a un nuevo modelo económico, que será especialmente perceptible en los territorios al sur del Guadiana.

\section{Cerámica de Retícula Bruñida}

Se conoce con este nombre a la cerámica hecha a mano que presenta decoración bruñida de tipo geométrico, realizada con un instrumento romo antes de la cocción de la pieza, cuando el barro está todavía fresco. La decoración se aplica sobre una superficie mate o bruñida y se extiende sobre las zonas visibles del vaso, generalmente en la parte interna del mismo, siendo escasas las piezas decoradas al exterior o en ambas superficies. Aunque los motivos más comunes son los de retícula, también aparecen líneas dispuestas oblicuamente y en paralelo, líneas onduladas, triángulos, etc., a veces repartidos de forma geométrica a modo de cuadrantes.

En Alarcos sólo se conoce un ejemplar de este tipo hallado en el sector Alcazaba. Se trata de un fragmento de pared de pasta negruzca, cocción reductora y desgrasante fino. Presenta decoración bruñida en su cara externa, formada por líneas verticales paralelas, delimitadas por otras horizontales (fg. 5:3).

Sobre el origen de la retícula bruñida se barajaron tres teorías que señalaban su procedencia oriental, céltico-europea y autóctona, si bien en la actualidad parece existir unanimidad en su consideración como producto de fabricación local y su relación con el mundo indígena que cabría calificar de tartésico precolonial y geométrico (Fernández et alii, 1994:61). Considerada como uno de los elementos más característicos del Bronce Final en la Andalucía Occidental, la opinión generalizada la sitúa en un horizonte contemporáneo de la cerámica monócroma tipo Carambolo, aunque se extingue después que ella (Arteaga, 1977:309; Abad, 1979:178; Ruiz Mata, 1979), con una cronología de los ss. IX-VIII y posiblemente el s. X a.C., según Ruiz Mata (1979:243) y que algunos autores elevan desde inicios del primer milenio a.C. hasta mediados del mismo, siendo más antiguas las cerámicas de Huelva (desde el cambio del II al I milenio hasta principios del s.VI a.C. (Fernández Jurado, 198889:209 y 237) que las del Bajo Guadalquivir.

Los paralelos más próximos a la pieza de Alarcos se encuentran en La Bienvenida, donde encontramos tres piezas con decoración bruñida 

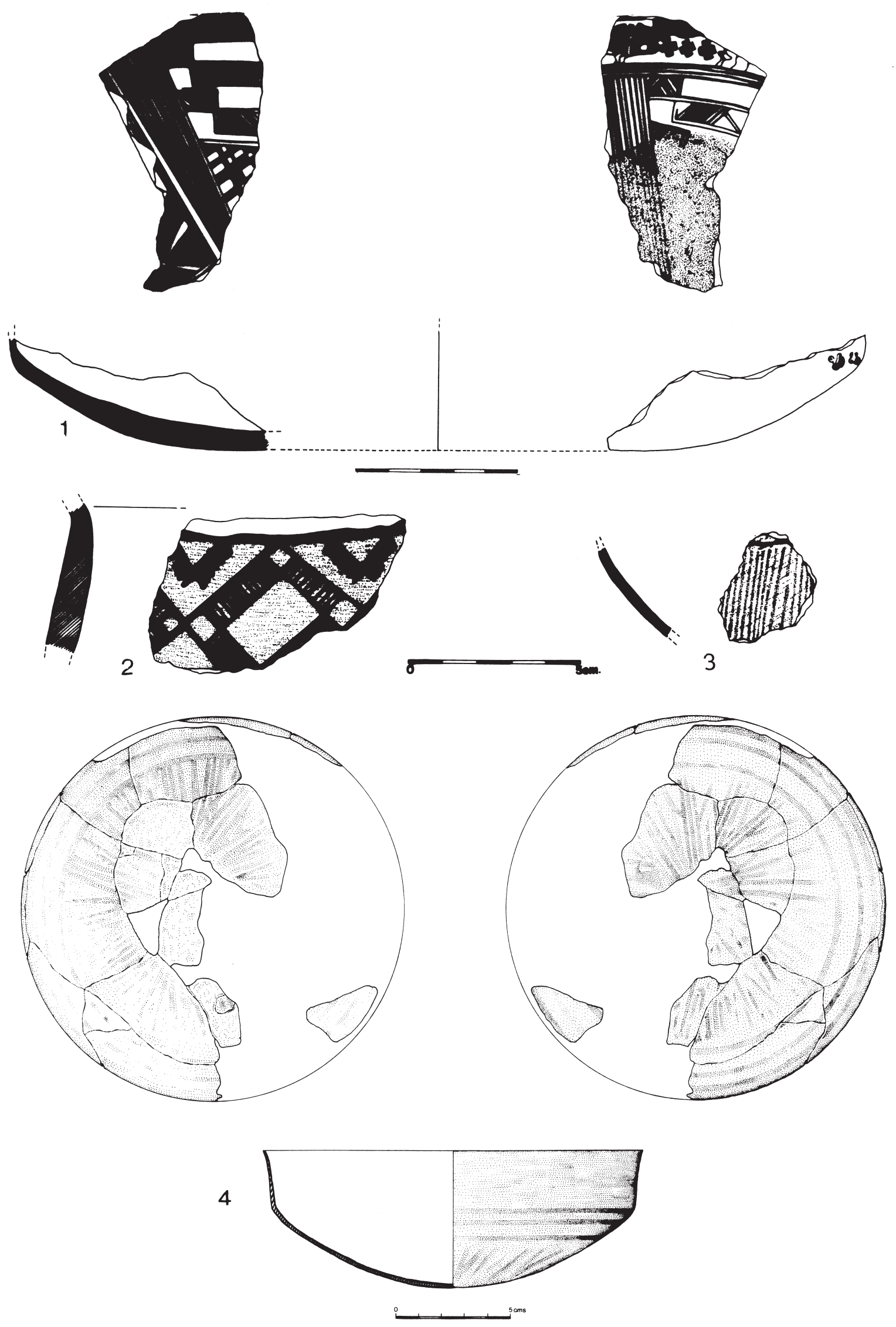

Figura 5. Cerámica de Carambolo: 1 y 2. Cerámica de retícula bruñida: 3. Cerámica pintada monocroma en rojo: 4. 
interior, dos del área de Huelva con una cronología de fines del s. VIII al VI a.C. y una tercera asociada a cerámica tipo Medellín y una copa samia de los ss. VII-VI a.C. (Fernández et alii, 1994:58-59, fg. 101:21). Estas piezas, sin embargo, presentan motivos diferentes a la de Alarcos, donde además la decoración se aplica en la parte externa.

Algo más distantes, pero también en el interior de la Meseta, se conocen dos fragmentos con decoración bruñida en La Capella (Madrid) que se asocian a piezas que presentan un marcado carácter meridional (cazuelas carenadas con decoración incisa, almagra...) fechadas en el s.VI a.C. (Blasco y Baena, 1989:220 y 231).

\section{Cerámicas a la Almagra}

La decoración a la almagra consiste en aplicar sobre la superficie de la vasija antes de cocerla un engobe rojo por inmersión o pincel, que puede cubrir las dos caras o sólo la exterior. En general estas piezas carecen de decoración geométrica o figurada, aunque en ocasiones un mismo recipiente puede estar decorado a la almagra y al grafito (Blasco et alii, 1991:113; Werner, 1988:191), como sucede en una de las piezas de Alarcos. En ocasiones aparecen asociadas a cerámicas tipo Carambolo, incisas y grafitadas (Buero Martínez, 1987-88:497).

Esta técnica fue utilizada en el Neolítico Medio andaluz y durante el Bronce Final se revitaliza en las zonas del sur y sudeste peninsular (González Prats, 1983:121), si bien aplicada sobre recipientes con formas propias de este momento, tanto de grandes dimensiones como en vasos pequeños, concretamente las características fuentes de carena alta. Estas últimas, más cuidadas, pueden estar bruñidas después de la cocción, lo que les confiere un brillo semejante al de los vasos de superficies negras bruñidas, cuyas formas repiten (Blasco et alii, 1991:113).

En Alarcos se conocen hasta el momento más de una treintena de fragmentos con esta decoración (fg. 6: 8 y 9). Bordes y galbos de pasta rojiza y cocción oxidante o gris oscura-negruzca y de cocción reductora. En general tienen desgrasantes medio o gruesos, aunque en algunas piezas son más finos. Los acabados varían del espatulado al alisado. Proceden de los sectores II y Alcazaba. Debido al estado de fragmentación de las piezas y el predominio de los galbos amorfos no es posible determinar la forma de los recipientes, si bien parecen corresponder a recipientes de tamaño medio o grueso a juzgar por su sección y ausencia de curvatura.
El área de dispersión de estas piezas es muy amplia y abarca prácticamente toda la Península: Andalucía, Sudeste y Meseta, siendo cada día mayor el número de yacimientos en los que se documenta su presencia, principalmente en el Sudeste, Madrid y Segovia (Blasco 1991:114). Su cronología se sitúa entre los ss. X-IX hasta ss. VI$\mathrm{V}$ a.C., siendo más tardía en la Meseta que en el Sur, ss. VII-VI a.C. (Buero Martínez, 198788:497).

En la provincia de Ciudad Real han aparecido dos ejemplares, de características diferentes en los estratos 13 y 12 b de la Bienvenida (Fernández et alii,1994:63) y en el Cerro de Las Cabezas (Esteban et alii, ep.)

Son relativamente abundantes en la fase II de Cástulo con una cronología de mediados del s.VII-principios del VI a.C., donde aparecen junto a cerámicas grafitadas, incisas, pintadas y sin decoración (Blázquez et alii, 1985:75).

\section{Cerámica Pintada}

La cerámica a mano con decoración pintada fue una moda que se desarrolló por casi toda la Península durante las primeras centurias del I milenio a.C., siendo uno de los elementos más característicos de la Edad del Hierro. Al ser también un fósil director de algunos grupos de C.U. recientes de Europa Occidental, ha sido considerada como prueba de las relaciones entre la $\mathrm{Pe}-$ nínsula Ibérica y Europa Continental durante el Bronce Final-I Hierro. Sin embargo, paralelamente aparece en el Suroeste otra cerámica pintada cuyo origen entronca con el horizonte geométrico del mundo mediterráneo (Blasco, 1980-81:75). La pintura se aplica después de cocida la pieza, lo que explica su escasa consistencia y su mala conservación y se hace sobre recipientes con formas típicas del Bronce Final- Hierro I. La gran variedad de formas, motivos y colores empleados, el contexto en que aparecen y el área de dispersión de las piezas ha llevado a algunos investigadores a agruparlas en una serie de tipos con denominaciones diferentes. Arribas y sus colaboradores (1974: 145-147) distinguen tres grupos: los yacimientos del Cerro del Real de Galera, Cástulo, Manzanares y Cerro de la Encina de Monachil; los del área del Suroeste (Carambolo, Nova-Velha, Cabezo de San Pedro y Asta Regia) y los del valle del Ebro, algunos de la Meseta Norte y otros del sureste de la meseta. Almagro Gorbea (1977:459-461) las denomina tipo Carambolo, tipo Medellin, tipo Tossal Redó, tipo Meseta y tipo Andaluz; y Ruiz Mata (198485:225) distingue entre las cerámicas tipo Guadalquivir I/Carambolo, tipo Guadalquivir 


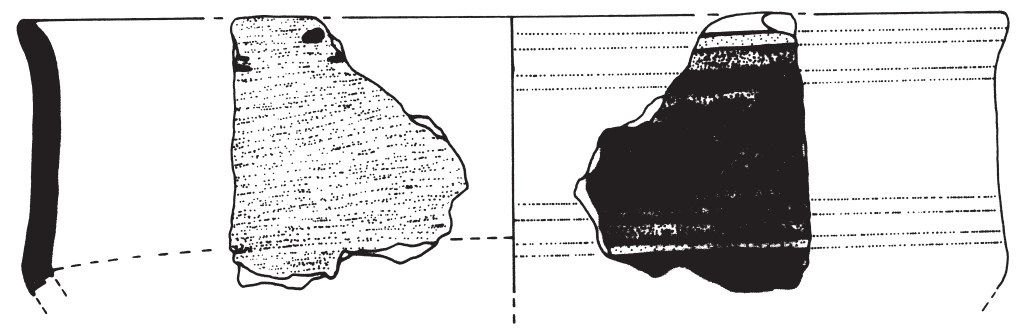

1
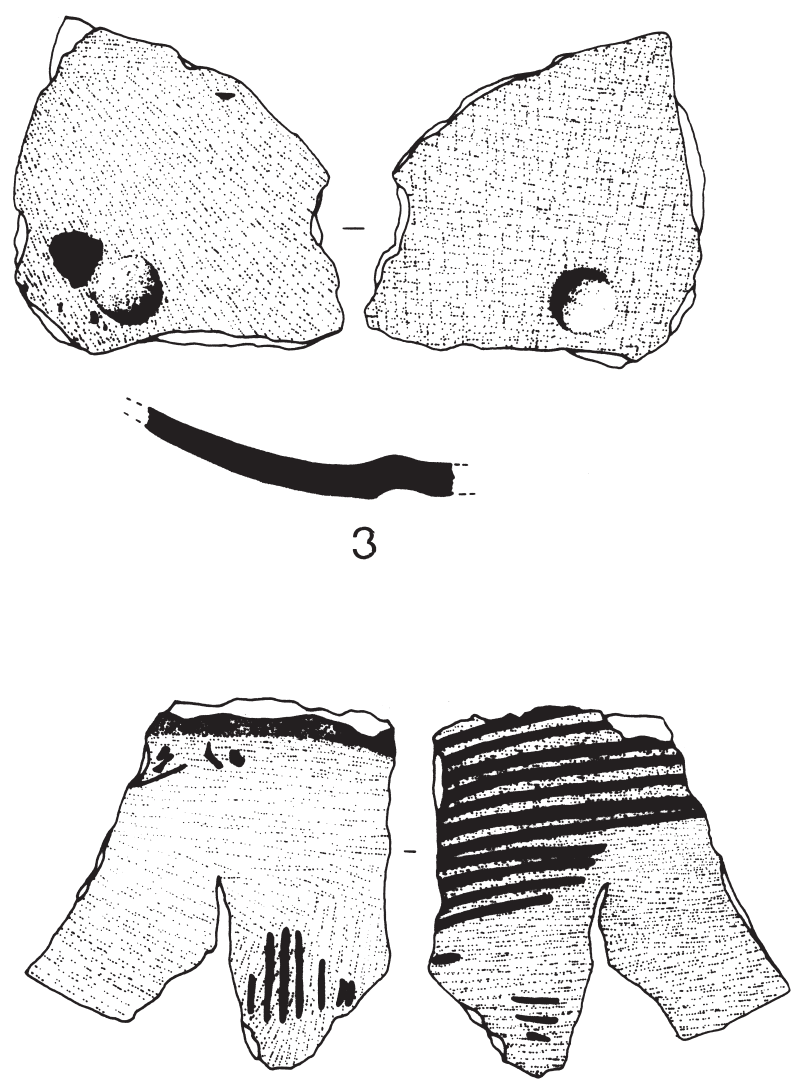

5

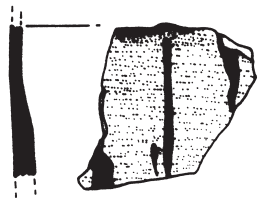

7

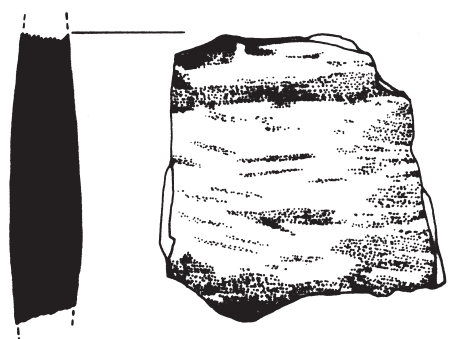

8
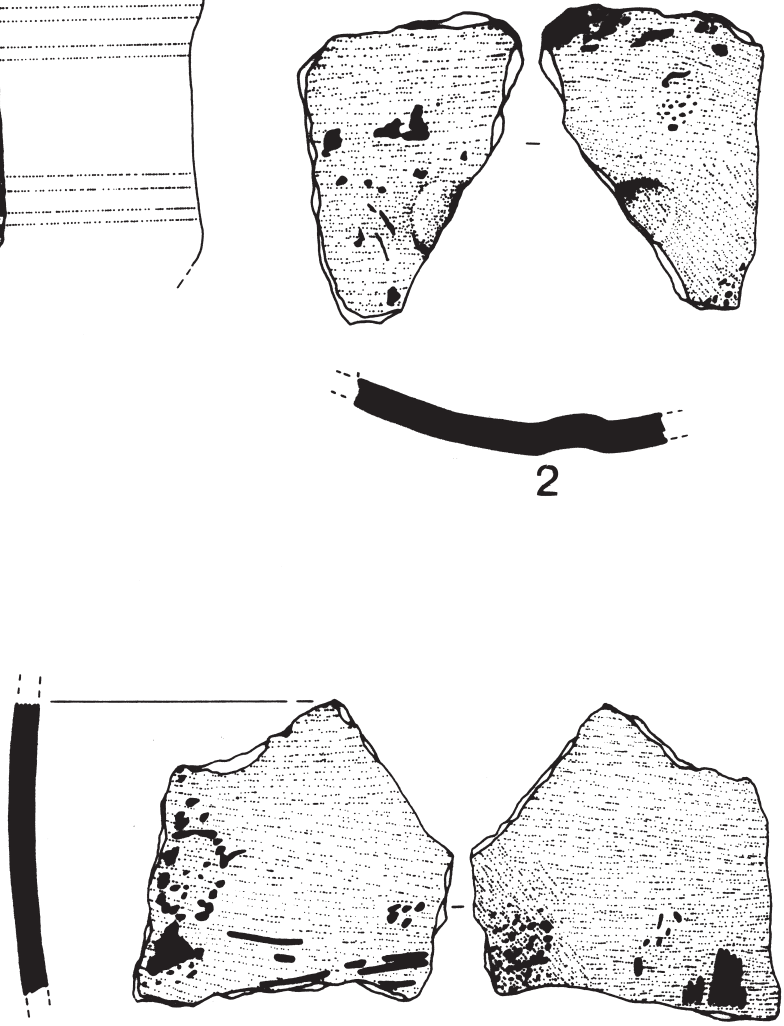

4

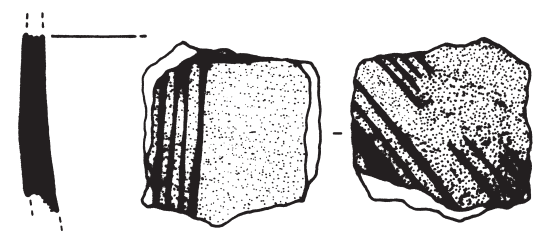

6

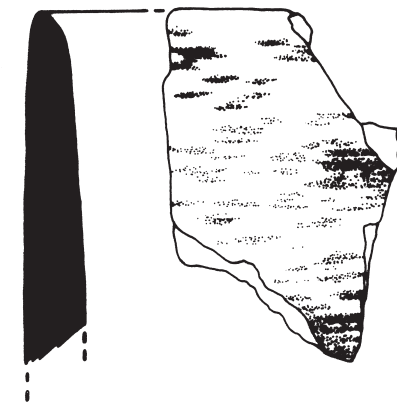

C)

Figura 6. Cerámicas pintadas bícromas rojo-amarillo: 1, 2, 3 y 4. Cerámicas pintadas monocromas en rojo: 5, 6 y 7. Cerámicas a la almagra: 8 y 9 . 
II/S. Pedro II, polícroma de Medellín, hallstáttica monocroma y hallsttática bícroma.

De los diferentes planteamientos de estos autores se deduce la dificultad que existe para definir este tipo de cerámica y la escasa precisión de los grupos establecidos. Esta imprecisión obedece, en opinión de Blasco (1981:78-79, al parentesco que tienen y a la imposibilidad de marcar diferencias sustanciales entre ellos. Tampoco su origen está claro, ya que si bien algunos autores asignan orígenes distintos a cada tipo, la mayoría admite una procedencia a partir de determinados grupos de C.U. tardíos de la Europa occidental e incluso se ha apuntado un origen peninsular. Sin embargo la escasez de hallazgos y la falta de contextos en muchos de ellos, dificulta llegar a conclusiones definitivas ni respecto a su origen, ni a las vías de penetración, ni siquiera a los tipos y variantes. Estas cerámicas están asociadas en la mayoría de los casos a cerámicas incisas, grafitadas o de acabados a "cepillo", si bien otras veces se enmarcan en un entorno claramente tradicional y autóctono (Blasco, 1981:80).

En Alarcos ha aparecido una amplia gama de cerámicas pintadas postcocción: las pintadas monocromas, entre las que se encuentran algunas del denominado tipo Carambolo, las monocromas en rojo propiamente dichas y las que tienen decoración bícroma en rojo y amarillo. En todos los casos se trata de recipientes de pequeño y mediano tamaño, con paredes finas y superficies my cuidadas, excepto en el caso de las cerámicas de Carambolo y superficies muy cuidadas.

\section{Cerámicas tipo Guadalquivir I o Caram- bolo.}

Se conoce con el nombre de estilo Carambolo a la cerámica pintada monocroma en rojo o castaño rojizo, con un conjunto de motivos que se aplican sobre vasos del Bronce Final prefenicio, aparecida principalmente en la región del Suroeste durante el Bronce Final tartésico. Recibe su nombre del yacimiento sevillano donde se localizaron las primeras piezas, pero Ruiz Mata (1984-85:225) la rebautiza con el nombre de "Guadalquivir" por considerar que se ajusta más a la realidad. Basicamente es una decoración rectilineal, con diseños geométricos más o menos complejos, que se aplica a pincel sobre engobe, bruñido o alisado, de tonos castaños o negros, lo que explica su escasa adherencia y su pérdida con la humedad.

De estas características han aparecido en Alarcos dos fragmentos, el primero de ellos perteneciente con toda probabilidad a una cazuela, está pintado completamente por ambas caras.
La parte interna presenta pintura de color castaño sobre engobe beige con motivos decorativos de carácter geométricos, a base de líneas horizontales y oblicuas formado rectángulos y rombos tramados. Al exterior, junto a la decoración geométrica de color rojo sobre fondo ocre se dispone otra de carácter figurado y apliques de metal que consisten en dos pequeñas incrustaciones de hilo de plata en forma de aspa en la zona próxima a la carena; bajo ellas aparecen dibujadas tres cruces junto a una serie de motivos figurativos difícilmente clasificables (quizás antropomorfa); en el resto de la superficie la decoración es de líneas paralelas horizontales y verticales enmarcando a rectángulos rellenos de trazos oblicuos. El extremo final de la pieza está quemado y su aspecto parece indicar que ha estado junto a metal. (fg. $5: 1$ ).

El segundo fragmento es un galbo entrante de forma casi rectilínea. $\mathrm{Al}$ interior presenta engobe negro muy bueno y espeso. La superficie exterior no tiene color uniforme y está pintada en rojo con motivos geométricos; en el centro aparece un rombo con los lados tramados y en la parte superior sendos ángulos de los que cuelgan flecos. La pieza tiene un brillo intenso de aspecto vitrificado (fg.5:2).

El origen y cronología de estas piezas no está claro. Para algunos autores se trata de una cerámica cuya decoración parece estar relacionada con el mundo geométrico mediterráneo y por ello con el inicio del proceso orientalizante, aplicada sobre formas indígenas del Bronce Tardío (Almagro Gorbea, 1977:459; Ruiz Mata, 1985). En cuanto a la cronología no hay unanimidad si bien la mayoría de los autores la sitúan entre la primera mitad del s.IX a.C. y mediados del s. VIII a.C. (Almagro, 1977; Ruiz Mata, 1985; Blasco, 1981: 78; Buero Martinez, 1987), otros defienden fechas más recientes s. VIII-VII a.C. (Pellicer, 1978.80:323) y ss. VII-VI a.C. (Aubet, 1982:387).

Su área de dispersión se centra en Andalucía Occidental y esporádicamente el Alentejo, Extremadura y Cástulo (Almagro, 1977:459), siendo los yacimientos del Carambolo, Valencino y la Universidad Laboral de Sevilla los que más materiales han proporcionado. Fuera de esta zona se conocen algunas piezas en Cáceres, el Llanete de los Moros (Montoro, Córdoba) y en Casa de Ranas (Valdepeñas, Ciudad Real) (Ruiz Mata, 1984-85:236).

Las dos piezas de Alarcos son las más septentrionales de la Península. Ambas tienen una gran calidad técnica, si bien la primera destaca por su originalidad y ofrece dos aspectos que la distin- 
guen del resto de las cerámicas conocidas hasta ahora: la asociación de decoración figurada y geométrica y la presencia de apliques de plata en forma de aspa, para el que no hemos encontrado ningún paralelo. En el primer caso los motivos decorativos que presenta esta pieza no se identifican con ninguno de los recogidos, en la tipología al uso (Buero, 1994) y es poco común encontrar ambos tipos decorativos en un mismo recipiente. Todo ello le confiere un aspecto de gran riqueza y le convierte, sin duda, en una pieza excepcional. Lamentablemente los dos fragmentos están descontextualizados ya que aparecieron en niveles medievales. Unicamente nos queda constatar su presencia en una misma zona -el Sector Alcazabaubicada en la parte más elevada del yacimiento, donde se han localizado otra serie de materiales pertenecientes al período orientalizante.

\section{Cerámica Monocroma en rojo.}

Esta cerámica caracterizada por su decoración pintada en rojo, semejante a la anterior, pero con motivos y formas diferentes, aparece durante el Bronce Final practicamente por toda la Península, y es conocida también como tipo Guadalquivir II/S.Pedro (Ruiz Mata,1984).

En Alarcos se conocen hasta el momento
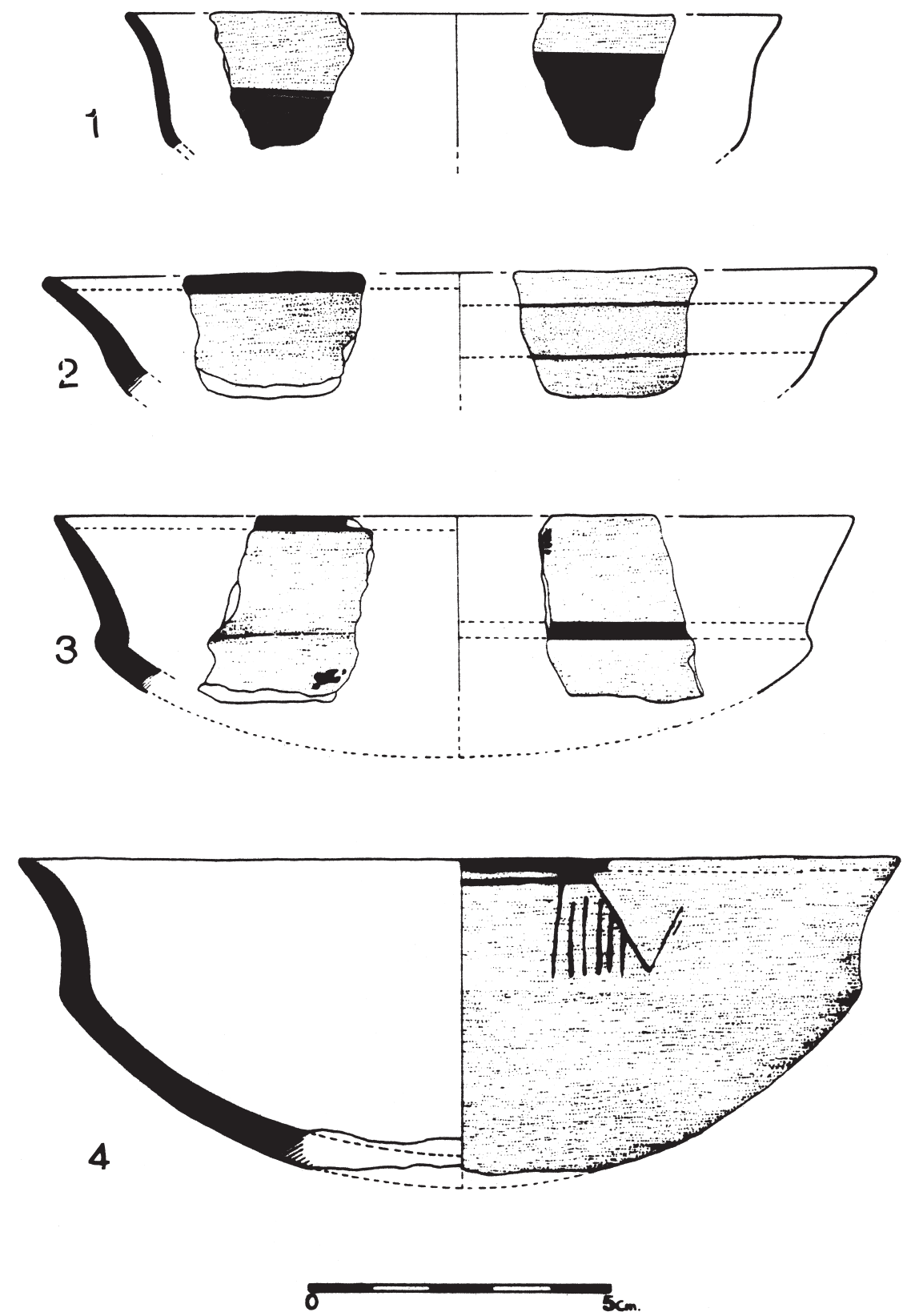

Figura 7. Cerámicas pintadas monocromas en rojo. 
once fragmentos, la mayoría procedentes del sector II (fg.7) y uno del sector IV-E (fg.5:4). Los primeros se hallaron en un nivel de habitat y el último corresponde a una urna cineraria. Sólo cinco dan forma -vasos carenados-, siendo el resto galbos exvasados de forma convexa, muy probablemente pertenecientes a pequeños cuencos de carena alta. Ocho tienen pasta gris oscura/negra y cocción reductora, dos cocción mixta y uno oxidante; el grosor varía de 1 a $5 \mathrm{~mm}$. Están pintados en su cara externa, interna o ambas a la vez, con decoración geométrica sencilla a base de líneas horizontales, oblicuas o verticales paralelas, a veces combinadas formando triángulos (fg. 7:4) o motivos radiales (fg. 5:4). Uno de los fragmentos tiene una pequeña cupulita central (fg. 6:2) semejante a las que aparecen en El Carambolo (Carriazo, 1973:540, lám. 10 no 29). En todos los casos el estado de conservación es muy deficiente.

Este tipo de cerámica aparece en la Bienvenida donde se ha vinculado al mundo tartésico y su hinterland (Zarzalejos et alii, 1994: 62-63) en los niveles de transición Bronce Final/Hierro I fines del s.VIII comienzos del s.VII a.C. y en el período orientalizante, mediados del s.VII- primera mitad del s.VI a.C. Algunos de los motivos y las formas son similares a los de Alarcos como sucede, por ejemplo, con el $\mathrm{n}^{\mathrm{O}} 40$, parecido al de las figuras 106-47 y 114-28 (Fernández et alii, 1994:242 y 244).

Su presencia en el Cerro de las Nieves, donde se hallaron algunos fragmentos con bandas pintadas en contextos y niveles de cerámicas a torno se explica, según sus excavadores, como un ejemplo de perduración de tipos antiguos durante el comienzo de la época ibérica (Fernández et alii, 1994: 119). En Cástulo los encontramos en la Fase I, fechada entre fines del s. VIII y primera mitad del s. VII a.C., y la fase II, con una cronología de mediados del s. VII -principios del s. VI a.C. (Blázquez et alii, 1985:224-227).

\section{Cerámica con decoración pintada bícroma}

La principal diferencia con respecto al tipo anterior estriba en que se utilizan dos colores para decorar, generalmente rojo-amarillo (variante mejor conocida en la Meseta) o blancorojo, que destacan sobre el fondo oscuro del vaso. Algunos autores hacen una distinción entre la cerámica bícroma que utiliza la técnica de la pintura amarilla o blanca sobre imprimación roma y aquellos que combinan estos colores directamente sobre la superficie bruñida del vaso (Carrasco et alii, 1986:219; Werner, 1990:77-80). Esta última técnica es la que aparece en Alarcos y es la más abundante en Andalucía oriental (Molina, 1978:218; Pellicer, 1986:440) y la Meseta (Werner, 1990:77-80), donde los colores predominantes son el rojo y el amarillo.

Con pintura bícroma, en rojo y amarillo, han aparecido en el cerro de Alarcos cuatro piezas procedentes de dos sectores muy distantes entre sí -II y III. En una de ellas, decorada en ambas superficies, la decoración consiste en dos líneas horizontales de color amarillo enmarcando a varias líneas oblicuas paralelas de color rojo y la interior conserva restos de pintura roja junto al borde (fg. 6:1). Los otros fragmentos tienen la decoración prácticamente perdida, conservándose restos de pintura roja y amarilla en ambas superficies (fg. 6: 2 y 4).

La cerámica bícroma aparece dispersa por Andalucía, Sudeste, Extremadura, Meseta y Valle del Ebro, estando su cronología en función del área geográfica en que se encuentra. En el Sudeste, Molina (1978:218) la denomina Tipo Real y la sitúa en torno al 850-750 a.C., siendo contemporánea de los vasos pintados del Bajo Guadalquivir. Ambos complejos muestran un carácter marcadamente mediterráneo frente a los grupos de la Meseta y el Valle del Ebro que, datados a partir del 750 a.C. conjugan tradiciones centroeuropeas con influencias mediterráneas más modernas y que perduran hasta los siglos VI-V a.C.

Para González Prats (1983:119), independientemente de que cada grupo tenga su propia personalidad, debieron existir conexiones entre ellos, a través de un doble flujo norte-sur, surnorte, un indicio de las cuales sería la similitud en los temas decorativos de algunos de estos tipos. Según Pellicer (1988:473) la aparición de cerámica con pintura bícroma en Andalucía oriental, en contextos del s.VIII a.C. avanzado, crea un problema, ya que se había señalado que el origen de este tipo de cerámica estaba en el Bajo Guadalquivir. Esto puede obedecer, según el autor citado, a que al ser una técnica meseteña penetrase en Andalucía a través del Sudeste, en dirección al Bajo Guadalquivir, donde se recibiría más tarde.

En la Bienvenida aparece la bicromía rojo amarillo y blanco amarillo con una cronología de mediados de mediados del s.VII y primera mitad del s.VI a.C. (Zarzalejos et alii, 1994:173-174). También en el Cerro de las Cabezas está presente la bicromía blanco -rojo en contextos del Bronce Final, con una cronología del s.VII a.C. (Vélez y Pérez, 1987: lám. IV, 28 y 30). En ambos casos, la bicromía es diferente a la de Alarcos donde está ausente el color blanco.

En Cástulo aparecen cuencos y cazuelas de 
carena alta, en rojo y amarillo en los estratos de la fase I, fechados a fines del s.VIII-primera mitad del s.VII a.C.( Blázquez et alii, 1985: 224227; Blázquez y Valiente, 1981:230; Carrasco et alii, 1986: 232).

\section{Cerámica Grafitada}

La cerámica grafitada es aquella sobre cuyas superficies se aplica una capa de grafito, lo que le confiere un color gris brillante. La técnica de aplicación del grafito se realizaría bien con un bastoncillo o diluyendo el polvo de grafito en algún liquido y luego se aplicaría con un pincel. Rouliere (1983: 209-220) al estudiar las cerámicas grafitadas bretonas y alsacianas plantea que el polvo de grafito fue mezclado con clara de huevo o bien con ceniza y agua; una vez aplicado se sometió al recipiente a una temperatura entre $800^{\circ}$ y $850^{\circ}$, el último paso en la fabricación de estas cerámicas sería la cocción, realizada en una atmósfera neutra o débilmente reductora.

El número de fragmentos de estas cerámicas halladas en Alarcos es de 29, de éstos 7 corresponden a bordes y el resto son galbos, por lo que resulta muy difícil la identificación de formas. Todas están fabricadas a mano, con paredes de grosor fino o medio, pastas de color rojizo y negro. Las superficies exteriores son de color pardo negruzco y están en la mayor parte de los casos bruñidas, sobre las que se ha aplicado un baño de grafito. Las superficies interiores son de color negro o rojizas y conservan en muchos casos restos de grafito (fg.8).

Sáez de Urturi (1983) distingue tres modalidades en la cerámica grafitada según el tipo decorativo:

1.- Cerámicas que presentan una capa de grafito en toda la superficie exterior y a veces en la interior.

2.- Cerámicas con una capa de grafito en el exterior sobre la que se aplica un diseño ornamental en otra pintura.

3.- Cerámicas que presentan el motivo decorativo en grafito sobre una superficie bruñida.

Las grafitadas del cerro de Alarcos pertenecen al tipo 1, con excepción de un fragmento del tipo 2. Esta técnica decorativa aparece en recipientes de pequeño tamaño con pastas bien depuradas y superficies alisadas, pero también se encuentra en recipientes con pastas mal decantadas, gruesos desgrasantes y cocciones deficientes; en ambos casos la capa de grafito se sitúa preferentemente en el exterior, si bien en algunos casos también aparecen en el interior. El pequeño tamaño de los fragmentos y la mala conservación del grafito difi- culta, en ocasiones, su identificación. Se localizan en el sector II, en el IV y en la Alcazaba.

Estas cerámicas aparecen en la Península Ibérica durante el Bronce Final y la Primera Edad del Hierro, aunque su cronología todavía no está clara ya que se trata de un tipo cerámico que por sus características ha pasado desapercibida durante mucho tiempo, dado que se confundía con la cerámica bruñida. Su dispersión se sitúa preferentemente en el Alto Ebro y en la Meseta oriental donde destacan el yacimiento de La Coronilla (Cerdeño y García Huerta, 1992:933 y ss.) y Pico Buitre (Valiente, 1982), ambos en la provincia de Guadalajara, donde se han encontrado otros yacimientos con este tipo cerámico. En los dos yacimientos citados las grafitadas aparecen en contextos del Bronce Final y la I Edad del Hierro.

Los hallazgos de gratifada en Cástulo pusieron de manifiesto, en su momento, que la dispersión de esta cerámica no se limitaba al alto Ebro y al oriente de la Meseta sino que se extendía hacia otros ámbitos culturales. En Cástulo el conjunto de grafitadas se fecha en el periodo orientalizante, siendo los niveles VI y VII los que han aportado un mayor número de fragmentos (Blázquez y Valiente, 1984: 407). Las grafitadas del poblado de Los Villares, en Caudete de Las Fuentes, pueden considerarse como una prolongación de la Meseta oriental. En este yacimiento aparecen en los niveles I, II y III y se fechan en los ss.VIII y VII a.C. (Mata Parreño, 1989;1991).

Hasta el momento los hallazgos más meridionales son los de Cástulo, por eso ofrece gran interés la aparición de este tipo cerámico en Alarcos. Los paralelos más próximos se sitúan en el poblado de Peñarroya, en Argamasilla de Alba, donde las grafitadas se asocian a cerámicas pintadas, impresas, incisas y a torno, un conjunto que ha sido fechado en el s.VI a.C. (García Huerta et alii, 1999:249-250). Cerámicas de este tipo también aparecen en el Cerro de la Cabezas (Esteban et alii, e.p.), aunque desconocemos el número de ejemplares y el nivel en el que se encontraron.

\section{Cerámicas CON Incrustaciones de BRONCE}

Este tipo cerámico con incrustaciones de metal es poco habitual, en Alarcos se han documentado tres ejemplares, uno de ellos que ha podido reconstruirse completamente se encontró en el sector IV, en un área de enterramiento, donde se utilizó como urna, mientras que los otros dos ejemplares son dos pequeños fragmentos de galbos que se hallaron en la Alcazaba (fg. 9). 

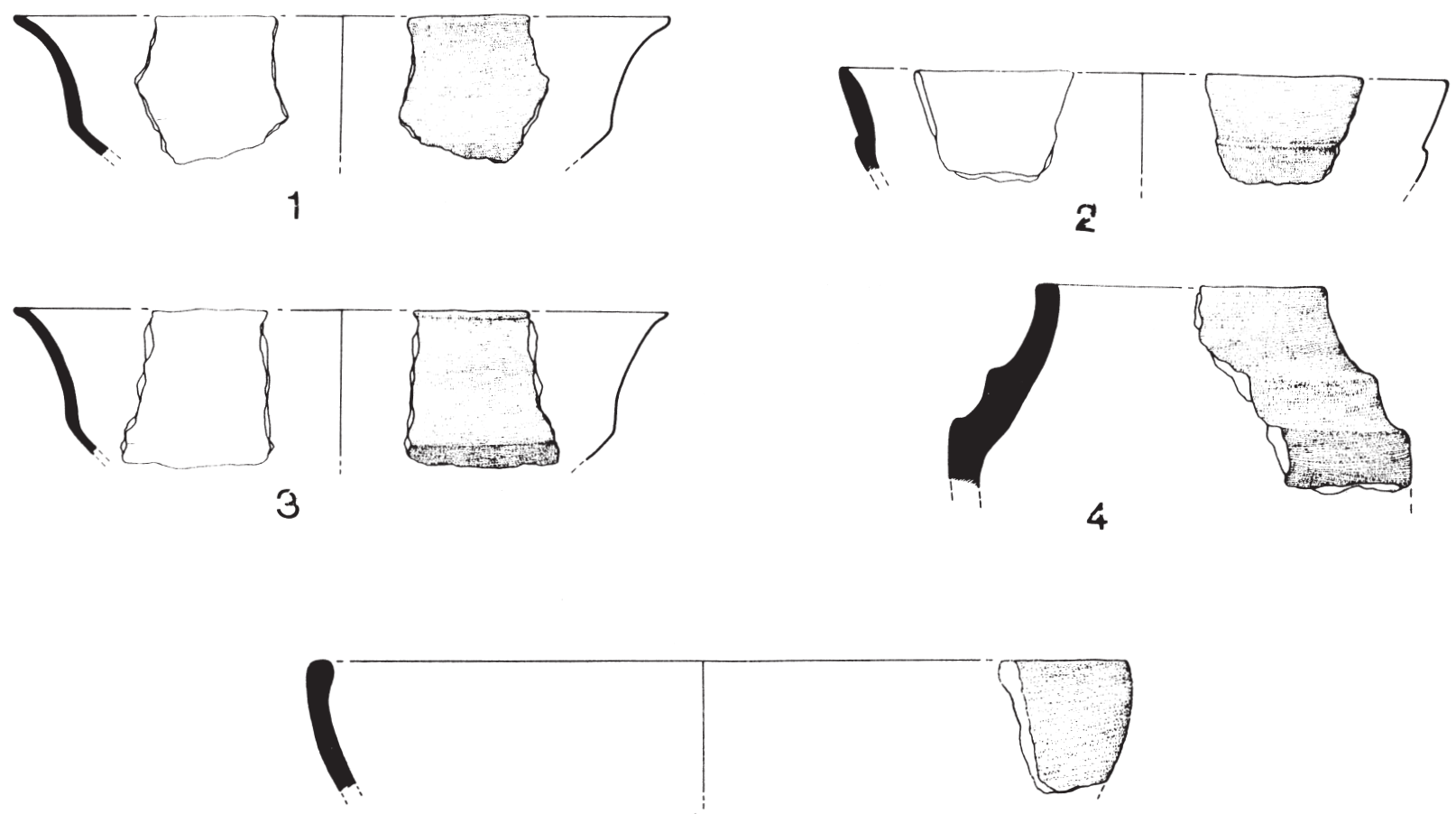

5
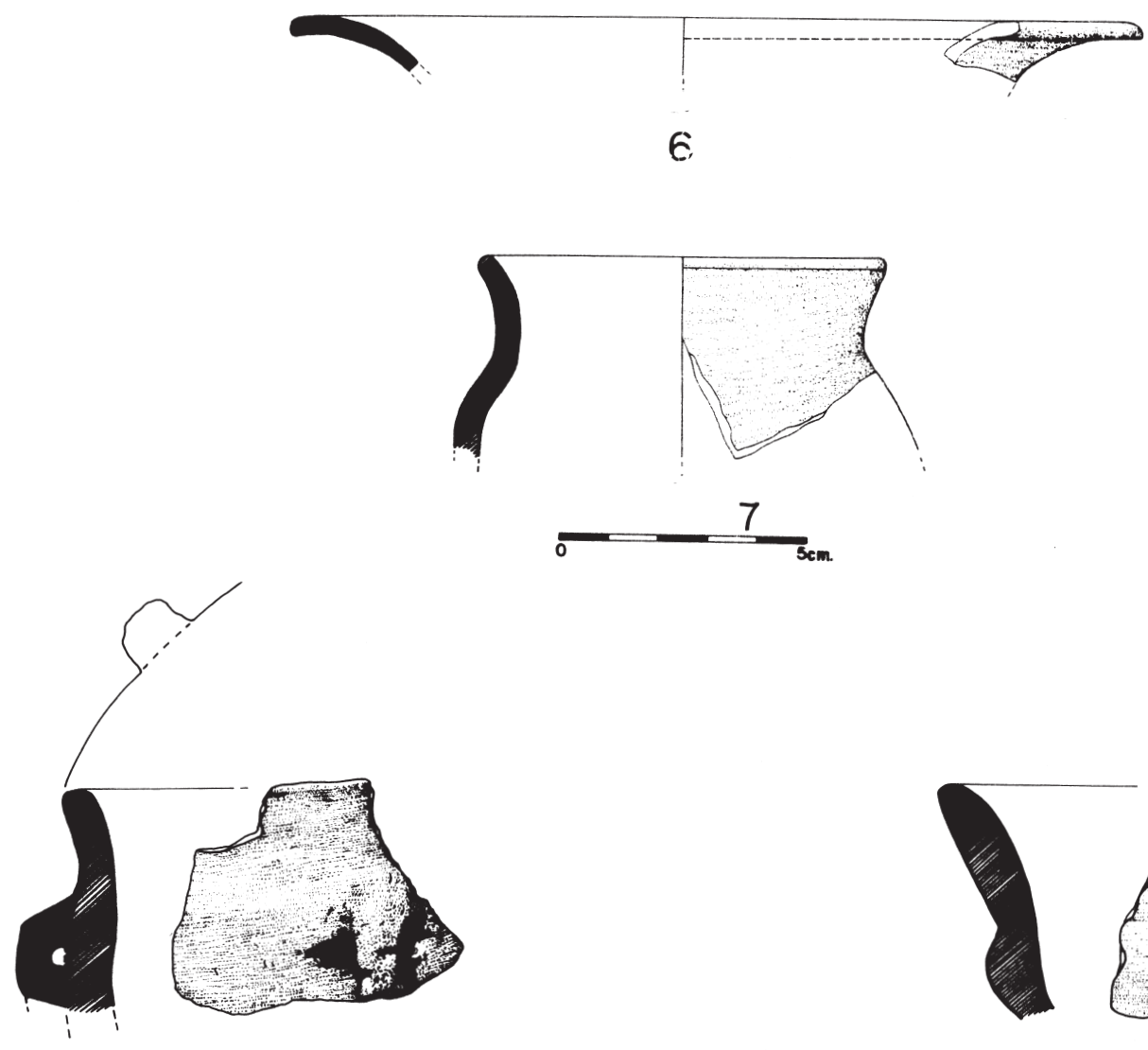

8
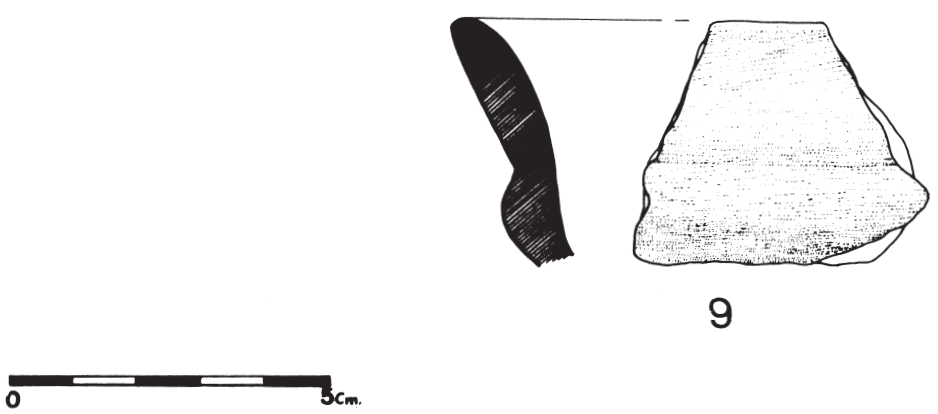

Figura 8. Cerámicas grafitadas. 
El recipiente entero está hecho a mano de pasta anaranjada y superficie negra bruñida, tiene el cuerpo globular bicónico, con pequeño cuello que acaba en un borde exvasado y biselado, el fondo es ligeramente cóncavo. En la línea de inflexión conserva tres botones de bronce o cobre de a modo de pezón (fg. 9:1).

Los otros dos fragmentos, están hechos a mano, tienen la pasta negra y las superficies bruñidas, uno de ellos presenta en la superficie exterior, justo encima de la carena lleva un botón de bronce y debajo de ese botón se conservan la impronta incompleta de otros dos botones bronce. El otro fragmento presenta en la superficie exterior un botón de bronce que consiste en una lámina de bronce.

Recientemente se ha publicado un trabajo en el que se analiza este tipo cerámico, su autora (Lucas, 1995) recoge un total de 21 yacimientos en el que se documentan cerámicas con incrustaciones metálicas. El mapa de dispersión de estas piezas refleja una importante concentración en Andalucía, donde se sitúan casi el 50\% de los yacimientos, o en zonas próximas como Extre-
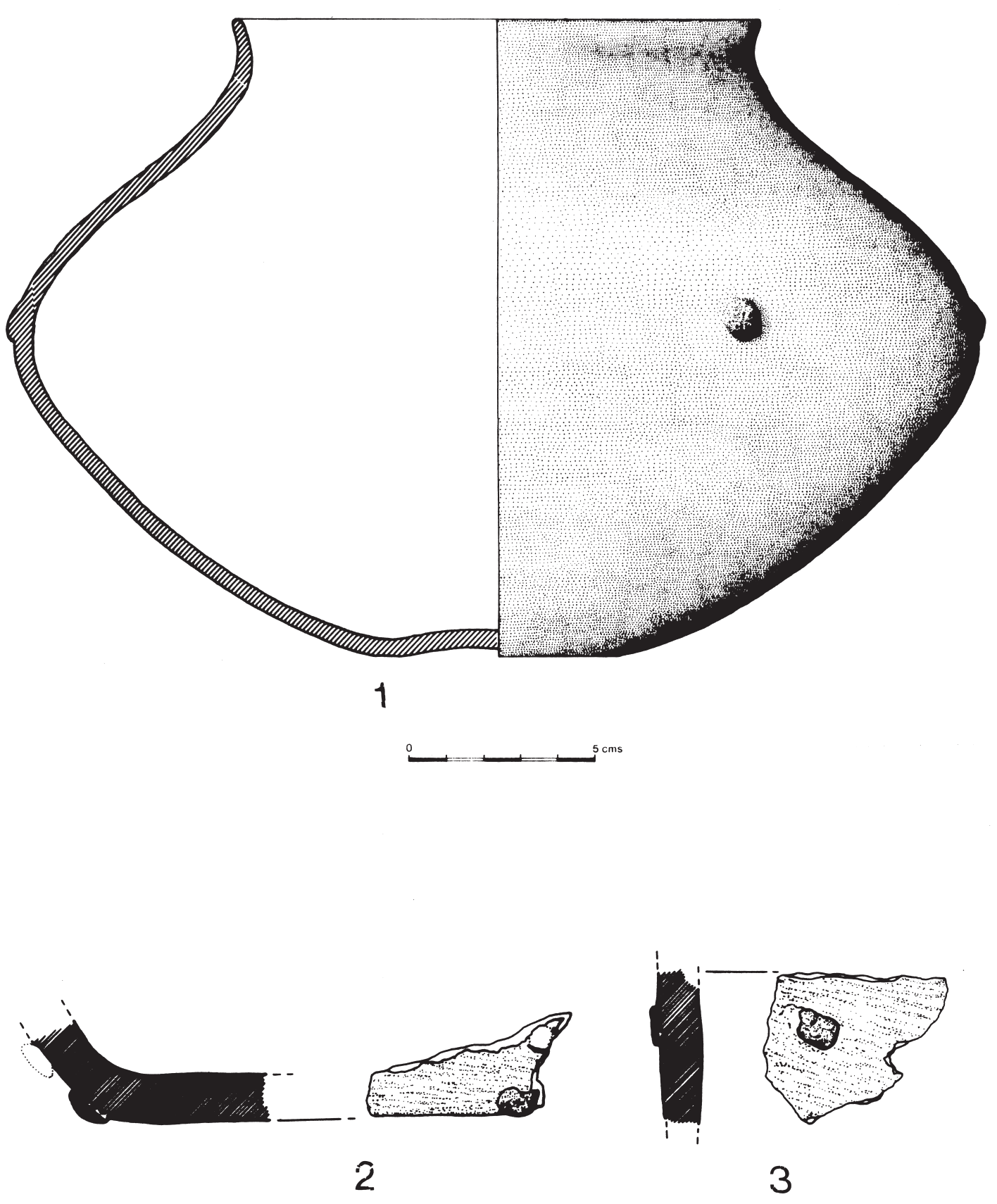

Figura 9. Cerámicas con incrustaciones de bronce. 
madura o el sur de la Meseta. Los ejemplares más septentrionales son los de Numancia, Soria, y el de la necrópolis de Luzaga en Guadalajara. En lo que se refiere a la cronología, no en todos los casos se conoce bien el contexto para realizar una buena adscripción cronológica, como ocurre con los mismos ejemplares de Alarcos. Uno de los mejores ejemplos es el recipiente hallado en la tumba de El Carpio, en Belvis de La Jara, dado que se trata de un contexto claramente cerrado en el que se encuentran, entre otros materiales, un gran lote de cuencos pintados, una jarrita gris con botones de bronce, un alabastrón, varios objetos de plata, entre los que destaca un vasito, materiales de bronce y dos fragmentos de hierro correspondientes a dos cuchillos; el conjunto ha sido fechado en los s.VII-VI a.C. (Pereira y Alvaro, 1988).

\section{Cerámica a Mano sin decoración}

Se trata de piezas hechas a mano que carecen de decoración pero presentan distintos acabados, desde los más groseros, cuyas superficies no tienen tratamiento especial a los más finos que están engobados, alisados, espatulados o bruñidos.

Este tipo de piezas es muy abundante en el yacimiento, por lo que hemos realizado una selección de las más representativas. En general se distinguen dos grupos bien diferenciados por su calidad y características técnicas. El primero está formado por una cerámica fina, probablemente empleada como una vajilla de mesa, en la que predominan los cuencos carenados y los platos de borde exvasado y cuerpo convexo. Están engobados y bruñidos o espatulados, tienen paredes con grosores entre $25 \mathrm{~mm}$, pasta gris oscura o negra, generalmente con cocción reductora y un barro muy decantado que utiliza desgrasantes de pequeño tamaño. El segundo lo integran las vasijas de cocina y almacenamiento de sección gruesa, vasos de paredes rectas o ligeramente convexas y hondas, vasijas de perfil globular con borde decorado con digitaciones y otras de borde engrosado (fg.11).

La existencia de estos dos grupos bien diferenciados en la producción cerámica a mano ha sido destacada como una característica del Bronce Final-Hierro I, frente a la relativa homogeneidad de las producciones anteriores (González Prats, 1983: 96) y es habitual encontrarlas en los yacimientos de este momento.

Dentro del grupo de las cerámicas de mejor calidad, predominan las fuentes y/o cuencos de carenas altas con cuerpo en forma de casquete esférico, si bien en lo referente a la orientación y tamaño del borde y la carena observamos una gran variedad que resumimos en los siguientes tipos:

1 - Borde exvasado, cuello cóncavo muy marcado y carena alta o media (fg. 10:1, 2, 5). A veces aparece con cierto grosor (fg. 10:4).

2 - Borde casi vertical y ligeramente cóncavo, con diámetro semejante al de la carena; aparece con sección muy fina (fg. 10:3,9) o bastante gruesa y con mamelón (fg. 10:6). Una variante de este tipo es un pequeño cuenco de borde vertical con hombrera en la carena, cuyo diámetro es superior al del borde (fg. 10:8). Algunas de las cerámicas pintadas presentan también esta forma.

3 - Borde exvasado y carena suave muy próxima a él, de grosor medio (fg.10:12, 13). Aparece también con el borde vertical y de sección más gruesa (fg. 10:10).

4 - Borde ligeramente exvasado, muy fino casi rectilíneo, con pequeña hombrera en la carena (fg. 10:7).

5 - Borde exvasado muy fino y carena suave (fg. 10:11).

Estas piezas pertenecen al grupo de cuerpo en forma de casquete esférico señalados por Blasco (1991:132) y que se sitúa en contextos orientalizantes y en general en los círculos culturales de la I Edad del Hierro. Entre ellos encontramos piezas con o sin hombrera, diferencia ésta señalada por A. González (1983:99-101), según el cual las piezas sin hombrera proceden de los cuencos carenados del Bronce Medio con su centro de irradiación en torno al valle del Duero. Mientras la presencia de hombrera se debe a las formas del Bronce del SO II, con una dispersión meridional. Estas fuentes con carena alta, cuyo origen todos los investigadores sitúan en la tradición indígena (Arteaga, 1977:307; Belén et alii, 1977:357); son los hallazgos más característicos del mundo tartésico.

Las cerámicas finas sin decoración son relativamente abundantes en yacimientos contemporáneos al de Alarcos y próximos a él, como La Bienvenida, fines del s.VIII o comienzos del s.VII a.C.; el Cerro de las Cabezas, s.VII a.C. (Pérez y Vélez, 1994:137-38) y en Peñarroya, Argamasilla de Alba (García Huerta et alii, 1999) donde algunos cuencos de carenas altas conviven con cerámicas a torno en un momento de formación del mundo ibérico. Muchas de las piezas de Alarcos encuentran paralelos en la fase I de Cástulo, como $\operatorname{los}^{\mathrm{O}}$ 6, 12, 15, 21, 22, 23 y 37 pertenecientes a la Fase I fechada a fines del s.VIII-primera mitad del s. VII a.C. (Blázquez, 1985: 933,101 y 105) o las 23, 24, 26 y 37 

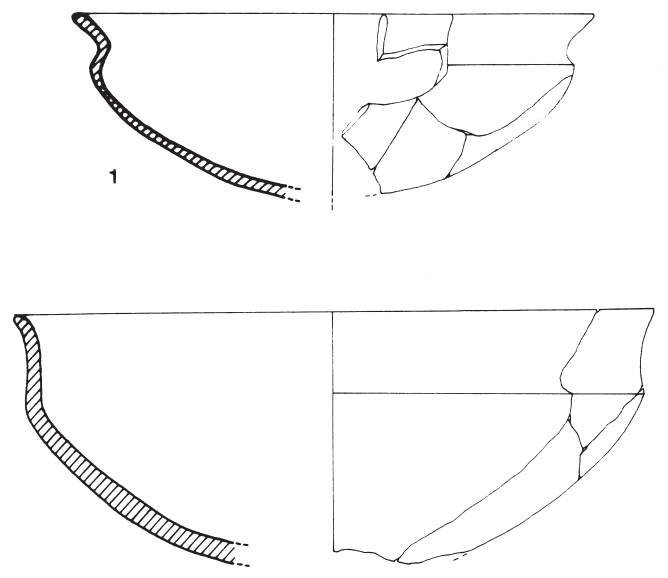

3
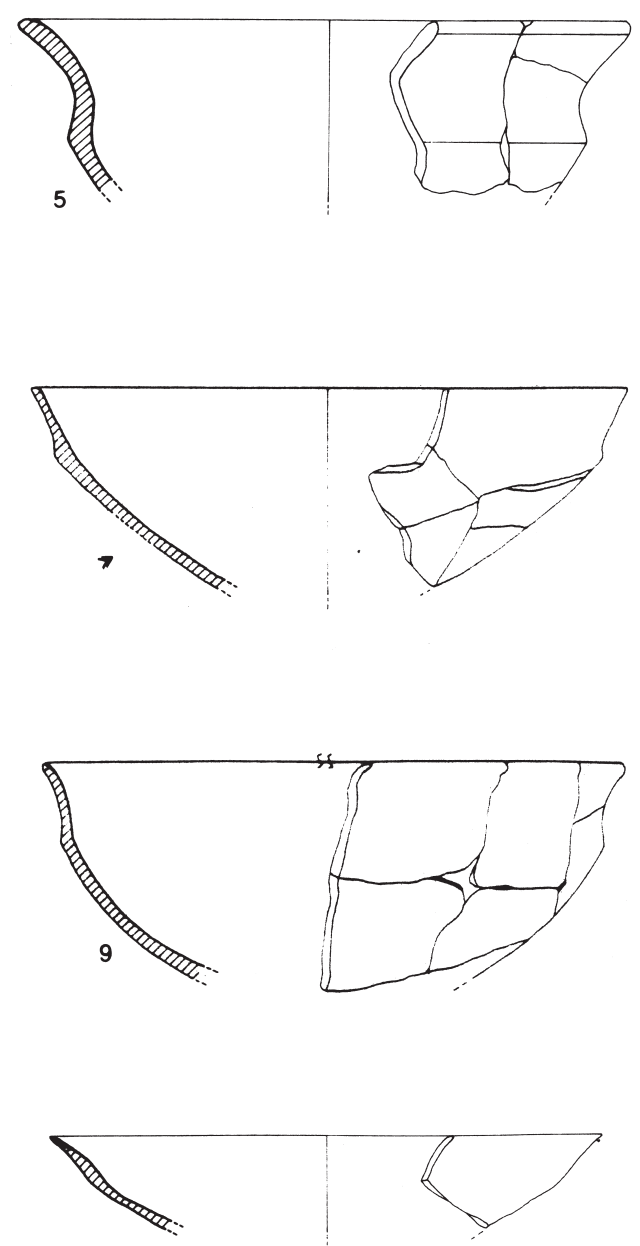

। ।
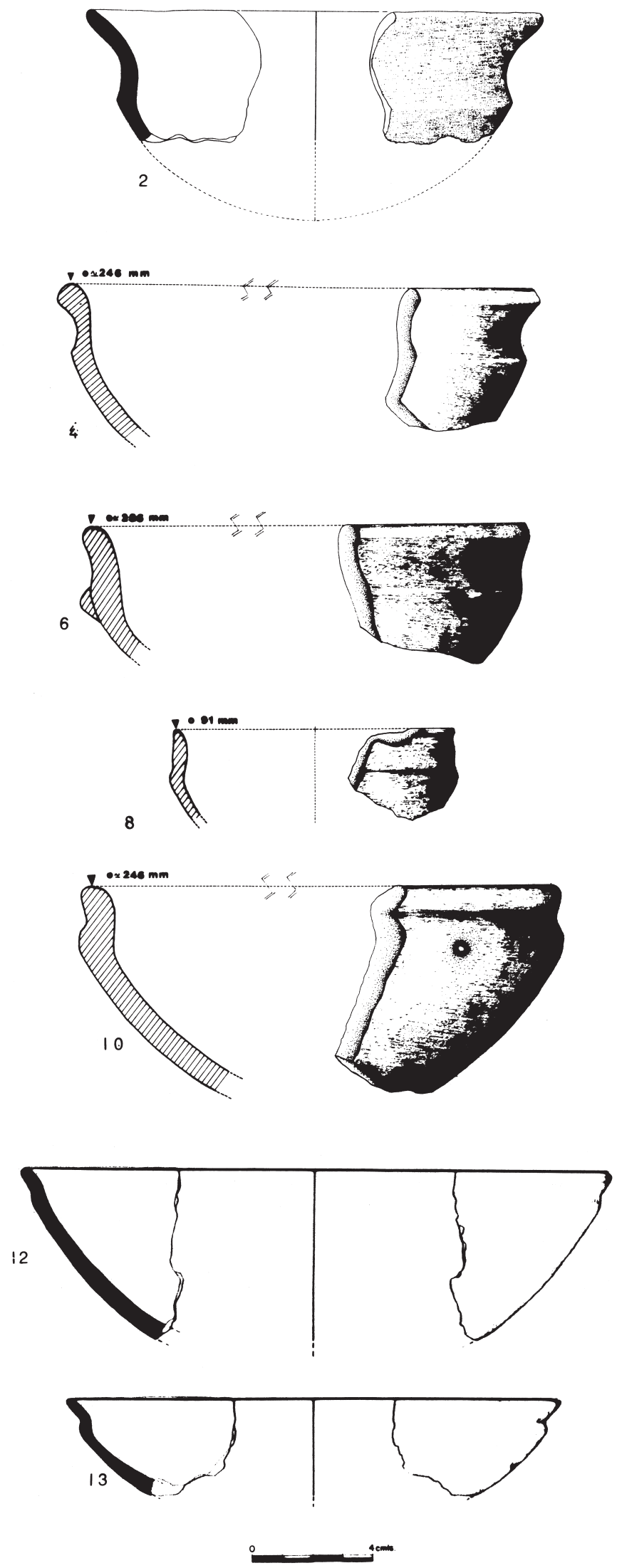

Figura 10. Cerámica común a mano. 

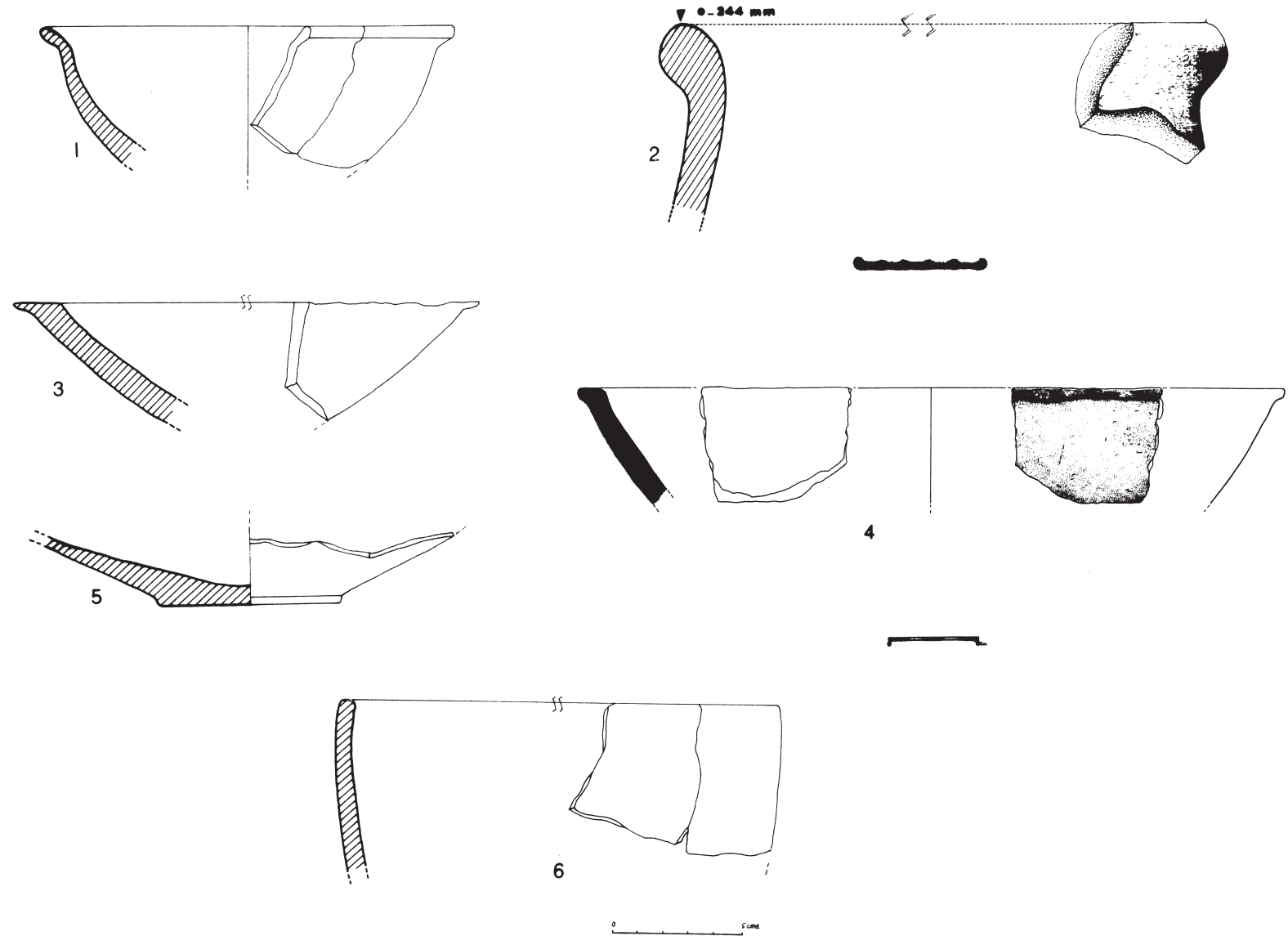

Figura 11. Cerámica común a mano

(Blázquez, 1985: 66 y 90). Los perfiles de estos vasos son los mismos que las de algunos de las pintadas y decoradas al grafito.

\section{ConClusiones}

El conjunto de piezas estudiadas pone de manifiesto la existencia de un momento de ocupación previo al desarrollo de la cultura ibérica en Alarcos, que se podría situar en el periodo de transición entre el Bronce Final- I Edad del Hierro. Este horizonte, que está empezando a perfilarse en varios yacimientos de la Submeseta Sur, como el Cerro de las Cabezas y La Bienvenida en Ciudad Real, el Carpio en Toledo y El Castellón en Albacete, entre otros, viene a llenar el aparente vacío de poblamiento que se produce en este ámbito entre el final de denominado Bronce Manchego y los inicios del Período ibérico.

El yacimiento de Alarcos es el único, por el momento, en el que documentamos la presencia de poblamiento continuado desde el Bronce Pleno. Los restos pertenecientes a esta etapa se han hallado en el espolón cuarcítico del extremo occidental del cerro, donde se localizan muros de mampostería y cerámicas a mano; el tipo de emplazamiento responde a las características habituales en los yacimientos de altura del Bronce Pleno, emplazados estratégicamente y con buenas condiciones defensivas.

Próximo a este espolón se sitúa el denominado sector Alcazaba, que coincide con la zona más elevada del cerro, donde se registra un mayor número de piezas del Bronce Final entre las que se encuentran las más relevantes de este período cultural. La presencia de estos elementos pone de manifiesto que esta zona del cerro fue la primera en ser ocupada de forma continuada a lo largo del tiempo, debido a que reúne las mejores condiciones defensivas y estratégicas. Sin embargo, la posterior construcción del castillo medieval ha alterado sustancialmente los antiguos niveles de ocupación sin que por el momento se hayan encontrado restos de estructuras constructivas correspondientes a esta fase del Bronce Final-Hierro I.

La aparición de cerámicas del citado horizonte en la ladera sur y sureste del cerro indica que la ocupación en este período no se limitó a su parte alta sino que se extendió también por 
estas zonas, lo que supondría un área de dispersión de unas 12 ha - superficie excavada hasta el momento.

No obstante, se observan ciertas diferencias entre las cerámicas halladas en los distintos sectores. Las cerámicas de Carambolo y boquique sólo aparecen en el sector Alcazaba. Estas piezas, raras y escasas, ya que proceden de otras áreas culturales, es probable que se consiguiesen mediante intercambios comerciales y su acceso estaría limitado a las élites que basarían su poder político en el control de productos foráneos, considerados como auténticos símbolos de status o bienes de prestigio. El ejemplo más representativo es una cerámica de Carambolo decorada con motivos pintados geométricos y figurados, con apliques de plata, se trata de una pieza verdaderamente excepcional para la que no hemos encontrado paralelos en ninguna parte, pero que sin duda no fue fabricada en Alarcos y cuya presencia revela los tempranos contactos entre esta zona y el área tartésica.

Si las futuras excavaciones confirman la presencia exclusiva de estos tipos cerámicos en el sector Alcazaba apoyará nuestra hipótesis de que nos encontramos ante la zona más antigua e importante del yacimiento. En el caso de que estas cerámicas aparecieran en otras áreas permitiría suponer que el nivel de desarrollo alcanzado por Alarcos en este momento es equiparable a otros yacimientos peninsulares como Medellin o Cástulo, poblados con los que debió mantener relaciones comerciales. También, resulta interesante señalar que la extensión de Alarcos en este momento, al menos de 12 ha, de las 33 ha que mide el yacimiento, no se ha documentado en ningún yacimiento de este período, ya que Medellín alcanza las 13,5 has pero en un momento posterior (Almagro y Martín, 1995: 118) y de Cástulo se desconocen dimensiones para estas fechas. Lo mismo sucede en los asentamientos de La Bienvenida y el Cerro de las Cabezas donde la extensión que conocemos de 10 y 14 has respectivamente, corresponden a todo el yacimiento sin que conozcamos las dimensiones de la $1^{\mathrm{a}}$ fase de ocupación de estos poblados.

La abundancia de material y la variedad de decoraciones permite señalar la existencia de relaciones, más o menos intensas, de los pobladores de Alarcos con las principales áreas culturales de nuestra Península en el Bronce Final- I Edad del Hierro, tales como la región tartésica del Sudoeste, la Alta Andalucía y el resto de la Meseta.

Los contactos con el ámbito tartésico, bien evidenciados por las cerámicas de Carambolo y retícula bruñida, entre otras, se producen en un momento temprano en torno al s.IX- s.VIII a.C. Por esta ruta del Sudoeste penetrarían también las estelas de tipo extremeño que han aparecido en diversas localidades de la provincia de Ciudad Real, siguiendo el curso del río Guadiana. El estudio de los materiales representados en dichas estelas permite fecharlas en los siglos IX-VIII a.C. y su presencia en esta zona viene a ratificar las relaciones que desde fecha muy temprana mantuvieron estos pueblos del interior peninsular con áreas tan dinámicas como el sudoeste. Otra muestra de la existencia de las tempranas relaciones entre ambas zonas es el hallazgo de un depósito de armas de bronce en Puertollano, municipio muy próximo al valle de Alcudia. El conjunto, muy original debido al pequeño tamaño de las piezas, está formado por 14 espadas, a medio camino entre el tipo pistiliforme y el de lengua de carpa. Los primeros análisis metalográficos muestran una gran semejanza con las de la Ría de Huelva, donde se encuentran los mejores paralelos para estas piezas.

Las cerámicas con incrustaciones de bronce también son de influencia meridional. Los paralelos más claros al de Alarcos se encuentran en Setefilla, donde aparece en la Fase II A del poblado que se fecha entre el siglo X - IX a.C. y en los túmulos $\mathrm{A}$ y $\mathrm{B}$ con unas cronologías mas recientes. Desde aquí es probable que estas piezas penetraran vía Medellín por el Guadiana hasta Alarcos y por el Tajo a la casa del Carpio en Belvis de la Jara.

Con respecto a las cerámicas pintadas y en concreto a las bícromas, no está clara su procedencia, ya que el reducido tamaño de los fragmentos no permite conocer ni su forma completa ni el desarrollo de la decoración, lo que se une a la gran confusión existente en torno a este tipo de cerámica. En el cercano yacimiento de La Bienvenida aparecen estas cerámicas en el nivel de ocupación más antiguo, fechado en el s. VIII e inicios del VII a.C. (Fernández Ochoa, et alii, 1994:58) lo que hace plantear a sus investigadores la vía de llegada de estos productos desde Extremadura, vía Medellín, donde se documentan estas cerámicas en las mismas fechas. Sin embargo, las piezas bícromas de Alarcos son más semejantes a las de Cástulo que a las documentadas en La Bienvenida y el Cerro de las Cabezas. La similitud entre los materiales cerámicos de Alarcos y Cástulo, donde están ampliamente representados gran parte de los tipos cerámicos de Alarcos, especialmente las cerámicas pintadas, permite plantear la llegada de estos productos desde la Alta Andalucía, por Sierra Morena. 
Los contactos con la Meseta norte están atestiguados por las cerámicas de boquique y las incisas rellenas de pasta blanca, típicas del grupo Cogotas I. Este horizonte, desconocido hasta hace algunos años en la Meseta Sur, empieza a alcanzar una amplia dispersión, ya que aparece en más de una docena de yacimientos toledanos (Carrobles, et alii, 1994:186); en Cuenca, y en Albacete, donde se han localizado en el Amarejo (Broncano y Blánquez, 1985:351-352) y el Castellón (López Precioso, 1993:69). Estos asentamientos vienen a llenar ese aparente vacío de la Meseta meridonal y explicarían la aparición de Cogotas I en Andalucía, en la que ya desde hace años se vienen documentando restos de este grupo, sin que se pudieran trazar las rutas de llegada, entre la Meseta y Andalucía. En la provincia de Ciudad Real los vestigios de Cogotas I aún son escasos, debido en gran parte a la escasez de investigaciones, a los restos hallados en Alarcos hay que añadir los procedentes de Plaza de los Moros en Malagón (Carrobles, 1994:186).

Estas relaciones ponen de manifiesto la importancia estratégica de este asentamiento desde el Bronce Final, momento en el que las comunicaciones con otras áreas empiezan a afianzarse. ¿En qué radica su riqueza?, ¿cómo podían adquirir estas gentes cerámicas de elevado coste como la cerámica de Carambolo?. Varios son los elementos que lo explican: la riqueza agrícola y ganadera de la vega del Guadiana y el control de las rutas mineras y las zonas de paso, elementos que continuarán manteniéndose en el período posterior de desarrollo de la cultura ibérica. Nuestra hipótesis con los datos disponibles para época ibérica es que la riqueza de Alarcos proviene fundamentalmente de la ganadería pudiéndose deducir una importante producción de lana y productos derivados. El clima de estos valles del Guadiana favorece esta riqueza así como su ubicación como zona de paso entre la Meseta y Andalucía que, sin duda, también fue utilizada en las rutas de la trashumancia.

Los elementos analizados permiten datar el inicio de este horizonte cultural en torno al s.IX, momento al que corresponderían las cerámicas de Carambolo y de retícula bruñida, lo que probaría los tempranos contactos de Alarcos con el área tartésica del Suroeste. Por esas mismas fechas debieron producirse contactos, más o menos esporádicos con otras gentes de la Meseta, cuando la cultura de Cogotas I estaba en su fase tardía. Las relaciones comerciales con el ámbito tartésico debieron mantenerse a lo largo de las siguientes centurias como indica la presencia de cerámica con incrustaciones de bronce. En este mismo período se constata también la exis- tencia de contactos comerciales con la Alta Andalucía, a través de Cástulo, con la que como ya hemos señalado reiteradamente mantiene muchas semejanzas.

En fechas más recientes debieron iniciarse los contactos con el área del Sudeste, desde donde posiblemente llegarían las cerámicas decoradas a la almagra abriendo el camino por el que más tarde llegarían las primeras importaciones griegas, tan abundantes en el yacimiento.

\section{Bibliografía}

Abad Casal, L. (1979): "Consideraciones en torno a Tartessos y el origen de la cultura ibérica". A.E.Arq., $\mathrm{n}^{\mathrm{o}}$ 52: 175-193.

Almagro Gorbea, M. (1977): El Bronce Final y el Período Orientalizante en Extremadura. B.P.H., vol. XIV.

Almagro Gorbea, M. y Martín, A. (eds.) (1995): Castros y Oppida en Extremadura. Madrid. Complutum Extra 4.

Arribas, A. et alii ( 1974): "Excavaciones en el poblado de la Edad del Bronce "Cerro de la Encina", Monachil (Granada). Corte estratigráfico n $\mathrm{n}^{\mathrm{o}} 3$. E.A.E, 81, Madrid: 145-147.

ArteagA, O. (1977): "Las cuestiones orientalizantes en el marco protohistórico peninsular." Cuadernos de Prehistoria de Granada, no 2: 301-320.

Aubet, M. E. ( 1982): "Un vaso a mano con decoración pintada de los Alcores de Carmona", Trabajos de Prehistoria, 39: 385

Belén, M. et alii (1977): "Los orígenes de Huelva. Excavaciones en los cabezos de San Pedro y La Esperanza". Huelva Arqueológica III. Huelva

Benítez de Lugo, L.; Hevia, P. y Esteban, G. (e. p.): El Bronce Final en la provincia de Ciudad Real: Componentes culturales y pautas de poblamiento. Actas del Congreso del Bronce Final en la Meseta. Molina de Aragón, 2001.

Blasco, C. (1980-81): "Reflexiones sobre la cerámica pintada del Bronce Final y la I Edad del Hierro en la Península Ibérica." Cuadernos de Prehistoria de la Universidad Autónoma de Madrid, no 7-8:75-92.

Blasco, C. Y BAENA, F. J. (1989): "El yacimiento de la Capelina (Pinto, Madrid) nuevos datos sobre las relaciones entre las costas meridionales y la submeseta sur durante la Primera Edad del Hierro". Cuadernos de Prehistoria de la U. Autónoma de Madrid, $\mathrm{n}^{\mathrm{o}} 16: 211-231$.

Blasco, C. y BARrio, J. (1986): "Excavaciones de dos nuevos asentamientos prehistóricos en Getafe (Madrid), N.A.H. n²7: 75-142.

Blasco, C. et alii (1991): "Excavaciones en el poblado de 
la Primera Edad del Hierro del cerro de San Antonio (T.M. Madrid). Arqueología, Paleontología y Etnografía, Madrid.

Blasco, C. (1992): "Etnogénesis de la Meseta Sur". Complutum. Paleoetnología de la Penín-sula Ibérica, no 2 - 3: 281-298.

Blázquez, J. M. y VAliente, J. (1980): "Cerámicas grafitadas del poblado de la Muela de Castulo". Trabajos de Prehistoria, 37. Madrid: 399-418.

Blázquez, J. M. y VAliente, J. (1981): "El poblado de la Muela y la fase orientalizante en Cástulo (Jaén), Phönizier im Wester, Madrider Beitrage, 8, Mainz am Rhein.

BlázQuez, J. M., García-Gelabert, M. P. y López, F. (1985): Cástulo V. E.A.E. $\mathrm{n}^{\circ} 140$, Ministerio de Cultura, Madrid.

Blázquez, J. M. y García-Gelabert, M. P. (1992): "Relaciones entre la Meseta y Oretania". Complutum. Paleoetnología de la Península Ibérica, no2-3: 45-55.

Broncano, S. y BlÁNQUeZ, J. (1985): El Amarejo (Bonete, Albacete). E.A.E., 139. Madrid.

Buero Martínez, S. (1984): "Los motivos naturalistas de la cerámica pintada del Bronce Final del SO peninsular". Habis: 354-364

Buero Martínez, (1987) "La cerámica decorada a la almagra del Bronce Final meridional”, Habis, 18-19: 485-514.

Carrasco, J; Pastor, M. y Pachón, J. A. (1981): "Cerro de la Mora (Moraleda de Zafayona, Granada). Campaña de 1979". N.A.H., 13.

Cerdeño, M. L., y García Huerta, R. (1992): El Castro de La Coronilla. Chera. Guadalajara (1980-1986). E.A.E., 163. Madrid.

Delibes, G. et alii (1995): "El tránsito Bronce FinalPrimer Hierro en el Duero Medio. A propósito de las nuevas excavaciones en el Soto de Medinilla (Valladolid)". Verdolay: 145-158.

Esteban et alii (e. p.): Materiales cerámicos de la transición del Bronce Final a la I Edad del Hierro del cerro de las Cabezas (Valdepeñas, Ciudad Real). Actas del Congreso del Bronce en la Meseta. Molina de Aragón, 2001.

Fernández, V. M.; Hornero, E. y Pérez Muga, J. A. (1994): " El poblado ibérico del Cerro de las Nieves (Pedro Muñoz). Excavaciones 1984-1991”. Arqueología en Ciudad Real, 8:.119-130. Toledo.

Fernández Jurado, M. (1988-89): "Tar-tessos y Huelva”. Huelva Arqueológica X-XI, 1. Diputación Provincial de Huelva.

Fernández OchoA, C. et alii (1994): Sisapo I. Excavacio- nes Arqueológicas en la "Bienvenida", Almodóvar del Campo, Ciudad Real. Patrimonio Histórico-Arqueología, Castilla-La Mancha, ${ }^{\circ} 10$.

Fernández-Posse, M. D. (1982): "Conside-raciones sobre la técnica de boquique". Trabajos de Prehistoria, 39:137-159. Madrid.

FERnÁndez Rodríguez, M. et alii (1995): "Constantes de poblamiento en Alarcos". Alarcos 95. El fiel de la balanza. Junta de Comunidades de Castilla - La Mancha, Toledo: 27-40.

FernÁndez Rodríguez, M., (2000): "El poblamiento ibérico en Alarcos (Ciudad Real)", en Patrimonio Arqueológico de C. Real. Métodos de Trabajo y actuaciones recientes. UNED Valdepeñas: 123-136.

FERnÁndez Rodríguez, M., (e.p): "La necrópolis del sector IV-E de Alarcos", Actas del Congreso de Incineraciones celebrado en la Universidad de Castilla-La Mancha, Ciudad Real.

García Huerta, R., Morales Hervás y Ocaña, A. (1999): "El poblado de la Edad del Hierro de Peñarroya. Argamasilla de Alba, Ciudad Real”. I Jornadas de Arqueología Ibérica en Castilla-La Mancha.

Gómez Toscano. Y Pérez Macías, J. A. (1991): “ El Pozancón (Trigueras, Huelva): Un poblado del Bronce Final tartéssico en la Campiña onubense". Cuadernos del Suroeste, $\mathrm{n}^{\circ}$ 2, Junta de Andalucía, Consejería de Cultura y Medio Ambiente. Museo de Huelva: 131-146.

GonzÁlez Prats, A. (1983): "Estudio arqueológico del poblamiento antiguo de la Sierra de Crevillente (Alicante)". Anejo I. Lucentum, Alicante.

González Prats, A. (1985): "Los nuevos asentamientos del final de la Edad del Bronce. Problemática cultural y cronológica". Arqueología del País Valenciano: Panorama y Perspectivas. Alicante.

López Precioso, J. (1993): "El Castellón (Hellín) y el Bronce Final inicial en Albacete". Jornadas de Arqueología Albacetense en la U.A.M. Madrid.

LuCAS, R. "Cerámicas con apliques de metal". B.A.A.A. $\mathrm{n}^{\circ} 35: 107-122$.

Mata Parreño, C. (1989): "Cerámicas grafitadas en Los Villares (Caudete de Las Fuentes.Valencia). XIX C.N.A., Valencia 1987. Zaragoza. 1989:1053-1064.

Mata Parreño, C. (1991): Los Villares (Caudete de las Fuentes, Valencia). Origen y Evolución de la cultura ibérica. Servicio de Investigación Prehistórica. Serie de Trabajos Varios. Valencia.

Pellicer, M. (1989): "El Bronce Reciente y los inicios del Hierro en Andalucía Occidental". Tartessos. Arqueología Protohistórica del Bajo Guadalquivir. Ed. Ausa. Sabadell. 
Pereira, J. (1994): "La transición del Bronce Final al Hierro en la Meseta Sur". Actas del Simposio La Edad del Bronce en Castilla-La Mancha. Toledo:37-85.

Pereira, J. y de Álvaro, E. (1988): "Una tumba de la transición Bronce-Hierro en la Meseta Sur: El Carpio (Belvis de la Jara, Toledo)". I Congreso de Historia de Castilla-La Mancha, t. III. Pueblos y Culturas Prehistóricas y Protohistóricas : 279-289.

PéReZ AvilÉs, J. y VÉLEZ, J. (1994): "El yacimiento protohistórico del cerro de las Cabezas (Valdepeñas, Ciudad Real)". Jornadas de Arqueología de Ciudad Real en la Universidad Autónoma de Madrid: 131-141.

ROULIERE, M. J. (1983): La cèramique dite graphitèe dans son contexte: le prémiere âge du Fer dans le Massif-Central. Thèse e 3 cycle. Univ. de Franche- Comte.

Ruiz Mata, D. (1984-85): Puntualizaciones sobre la cerámica pintada tartésica del Bronce Final -estilo Carambola o Guadalquivir I. Homenaje a Gratiniano Nieto. Cuadernos de Prehistoria y Arqueología de la U. Autónoma.

SÁEZ de UrTuRI, F. (1983): "Estudio de las cerámicas gra- fitadas en yacimientos alaveses", Estudios de Arqueología Alavesa, $\mathrm{n}^{\circ}$ 11, Vitoria Gastein.

VAliEnte, J. (1982): "Cerámica grafitadas de la comarca segontina". Wad-Al Hayara, no 9:117-135.

Valiente, J. (1986): "El cerro de Almudejo (Sotodosos, Guadalajara). Un asentamiento de transición del bronce al Hierro". Wad-Al Hayara ${ }^{\circ}$ 13: 71-90.

Werner, S. (1987-1988): " Consideraciones sobre la cerámica con decoración grafitada de la Península Ibérica", Kalathos, no 7-8: 185-194.

WERNER, S. (1990): La cerámica pintada geométrica del Bronce Final y de la $7^{a}$ Edad del Hierro. Ed. La Muralla, Madrid.

Zarzalejos, M.; Fernández Ochoa, C.; Hevia, P y Esteban, G. (1994): "Excavaciones en la Bienvenida (Ciudad Real). Hacia una definición preliminar del Horizonte históric-arqueológico de la Sisapo antigua". Jornadas de Arqueología de Ciudad Real en la Universidad Autónoma de Madrid: 169-194. 